\title{
Human promoter genomic composition demonstrates non-random groupings that reflect general cellular function Markey C McNutt ${ }^{1,2}$, Ron Tongbai ${ }^{1}$, Wenwu Cui ${ }^{1}$, Irene Collins ${ }^{1}$, Wendy J Freebern ${ }^{1,3}$, Idalia Montano ${ }^{1}$, Cynthia M Haggerty ${ }^{1}$, GVR Chandramouli and Kevin Gardner*1
}

Address: ${ }^{1}$ The Advanced Technology Center, Laboratory of Receptor Biology and Gene Expression, National Cancer Institute, Bethesda, Maryland 20892-4605, USA, ${ }^{2}$ The University of Texas Southwestern Medical Center at Dallas, TX, USA and ${ }^{3}$ Bristol-Myers Squibb, Syracuse, NY, USA

Email: Markey C McNutt - markey.mcnutt@utsouthwestern.edu; Ron Tongbai - tongbair@mail.nih.gov; Wenwu Cui -cuiw@mail.nih.gov; Irene Collins - collinsi@mail.nih.gov; Wendy J Freebern - freeberw@mail.nih.gov; Idalia Montano - montanoi@mail.nih.gov; Cynthia M Haggerty - haggertc@mail.nih.gov; GVR Chandramouli - chandrag@mail.nih.gov; Kevin Gardner* - gardnerk@mail.nih.gov

* Corresponding author

Published: 18 October 2005

BMC Bioinformatics 2005, 6:259 doi:10.1186/147|-2105-6-259
Received: 17 May 2005

Accepted: 18 October 2005

This article is available from: http://www.biomedcentral.com//47/-2/05/6/259

(C) 2005 McNutt et al; licensee BioMed Central Ltd.

This is an Open Access article distributed under the terms of the Creative Commons Attribution License (http://creativecommons.org/licenses/by/2.0), which permits unrestricted use, distribution, and reproduction in any medium, provided the original work is properly cited.

\begin{abstract}
Background: The purpose of this study is to determine whether or not there exists nonrandom grouping of cis-regulatory elements within gene promoters that can be perceived independent of gene expression data and whether or not there is any correlation between this grouping and the biological function of the gene.
\end{abstract}

Results: Using ProSpector, a web-based promoter search and annotation tool, we have applied an unbiased approach to analyze the transcription factor binding site frequencies of 1400 base pair genomic segments positioned at 1200 base pairs upstream and 200 base pairs downstream of the transcriptional start site of 7298 commonly studied human genes. Partitional clustering of the transcription factor binding site composition within these promoter segments reveals a small number of gene groups that are selectively enriched for gene ontology terms consistent with distinct aspects of cellular function. Significance ranking of the class-determining transcription factor binding sites within these clusters show substantial overlap between the gene ontology terms of the transcriptions factors associated with the binding sites and the gene ontology terms of the regulated genes within each group.

Conclusion: Thus, gene sorting by promoter composition alone produces partitions in which the "regulated" and the "regulators" cosegregate into similar functional classes. These findings demonstrate that the transcription factor binding site composition is non-randomly distributed between gene promoters in a manner that reflects and partially defines general gene class function.

\section{Background}

Amidst a continuous bombardment of diverse stimuli from the external environment, metazoan organisms have adopted multiple strategies to respond specifically and decisively to a myriad of extracellular events. The biological map that determines this is encoded within the gene regulatory regions of the genome. Deciphering the inherent language in these encrypted codes is a major challenge 
of the post-genomic era. The search, retrieval and examination of the upstream regulatory sequences of eukaryotic genes coupled with empirical determination of their transcriptional regulatory function has yielded a wealth of potentially useful information relevant to the sequencespecific codes used to dynamically coordinate the spatial, temporal, and kinetic assembly of gene regulatory complexes at specific genes [1]. Cells must orchestrate this coordinated gene expression in order to efficiently execute the multitude of cellular programs that direct specific functions.

Essential components of controlling networks that modulate cellular programming are the regulatory sequences or transcription factor binding sites (TFBS). TFBSs comprise the basic unit of information stored within the upstream genomic regions located near the transcription start site (TSS) of most genes $[1,2]$. These typically $8-15$ bp nucleotide sequences interact specifically with the DNA-binding domains of several hundred different transcription factors. Since it is widely accepted that the TFBS arrangement and composition of these upstream regulatory regions are the fundamental determinants of gene expression, many software applications and computational approaches have been developed to sort and identify TFBSs in the regulatory regions of genes determined to have similar patterns of expression [3-5]. One popular approach is based on a software algorithm that compares the potential binding site base frequencies against an established database of empirically determined nucleotide frequencies derived from published biological studies [5]. The resulting position weight matrixes (PWM) are then used to search for and characterize potential binding sites dependent on their statistical similarities to known TFBSs. A major goal of this approach is to analyze cooccurring TFBS frequencies in the regulatory regions of similarly regulated genes as a means of defining transcriptional pathways or networks that orchestrate the coexpression. Most biologists measure steady state RNA levels as an indicator of gene expression. Thus, the linkages between TFBS occurrence and gene expression will undoubtedly be imperfect due to the fact that: 1) steadystate levels of expressed mRNA are a combined result of both active transcription and mRNA turnover; 2 ) indirect regulation of transcription factors by post-translational modification or other transcriptional components is a common control mechanism in metazoan biology; and 3) most PWM libraries are derived from empirical data sets and therefore have limited inclusiveness $[1,6-8]$. Nonetheless, focused and global analysis of gene promoter composition has the potential of yielding important insight into gene regulation.

Recent efforts to define a common vocabulary to describe the function of all genes through the use of established
Gene Ontology terms has provided a standardized approach of analyzing genes, clustered by any objective criteria, with respect to their cellular function $[9,10]$. Combining the analysis of gene promoter composition with gene ontology annotation provides a novel and innovative means through which linkages between gene regulatory networks and programs of cellular function can be identified and defined.

In this study, we analyzed the transcription factor binding site composition of 1400 bp promoter regions defined as $1200 \mathrm{bp}$ upstream and $200 \mathrm{bp}$ downstream of the transcription start site of 7,298 genes previously characterized in a recent microarray study of the kinetic patterns of gene expression in a mitogen-stimulated human leukemic Tcell line [11]. Though the composition of TFBSs in these 7,298 genes show very poor correlation with the measured global kinetic patterns of steady-state gene expression, independent partitional clustering of the TFBS composition within these 1400 bp regions "in silico" produced definable non-random gene groups for which distinct classes of ontology terms were found more frequently than expected by random chance. Moreover, analysis of the TFBSs that were most significant for distinguishing these gene groups revealed strong correlations between the ontology terms of the transcription factors predicted to bind the controlling gene regulatory regions and the ontology terms of the clustered genes themselves; thus, establishing a functional link defined by the ontology of the regulated gene and that of its regulators (TFBSassociated transcription factors). Refinement of this approach may provide a general means of defining the regulatory genomic templates upon which transcriptional networks are integrated to control specific programs of gene expression and cellular behavior.

\section{Results}

The process of T-cell activation has been a widely applied model system for the study of stimulus-evoked transcriptional control [12]. Prior analysis of this system has shown that many of the molecular signaling pathways initiated during T-cell activation converge on RAS-dependent effectors coupled with integrated secondary messenger signaling mediated by increased calcium influx. Thus, a common means of achieving robust activation of lymphoid cell lines is through pharmacological manipulations brought about by the addition of phorbol ester and calcium ionophore to resting cells. Several recent studies have profiled time dependent changes in steady-state gene expression of mitogen-induced T-cells to search for transcriptional pathways that appeared to be disproportionately effected based on a time series analysis of the data $[11,13]$. The fundamental linkage between transcriptional pathways and the expressed gene is the presence of recognition motifs or TFBS within the upstream regulatory 
(a) K-means Clustering of Expression Data
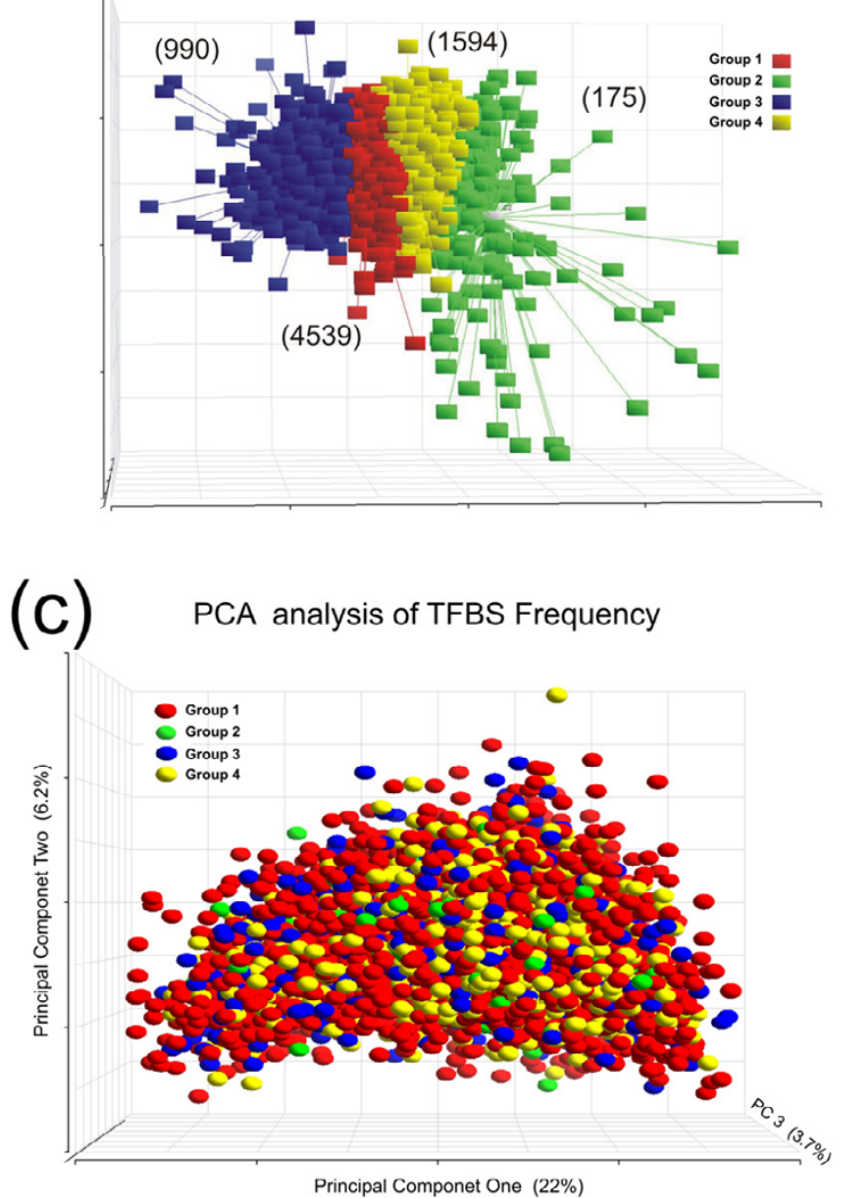

(b) Time Series Profile of Gene Expression Data

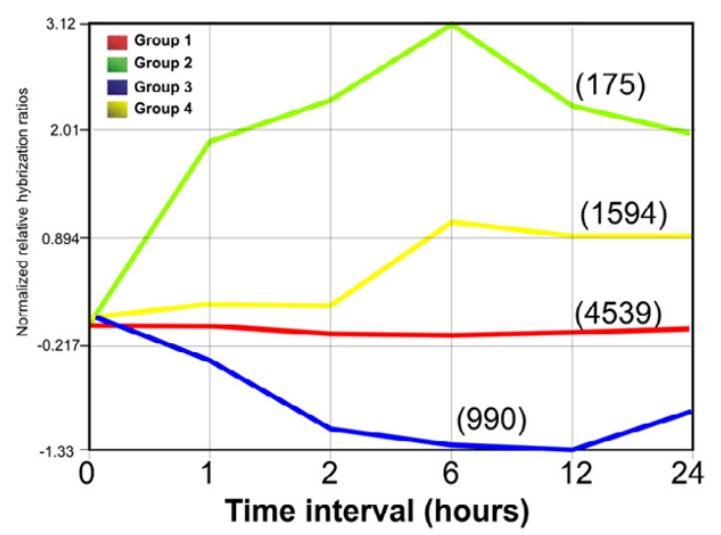

(d) K-means Clustering of TFBS Frequency

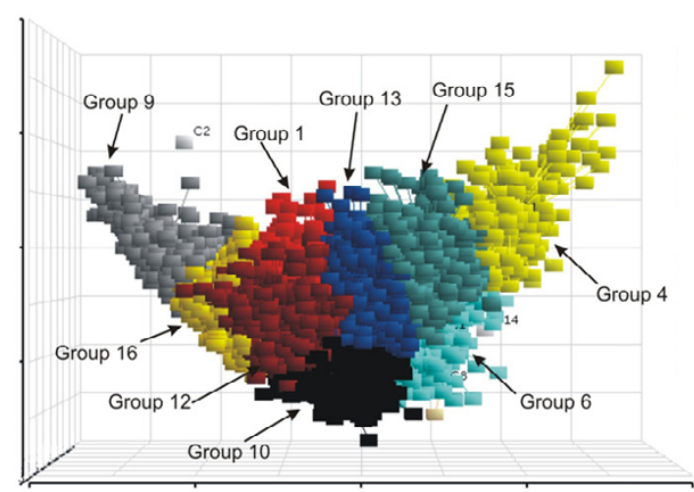

Figure I

Cluster analysis of gene expression data set from mitogen stimulated T-cells compared to promoter TFBS composition. (a) K-means cluster analysis of cDNA expression profiles of phorbol ester and ionomycin stimulated Jurkat Tcells collected at $0,1,2,6,12$, and 24 hours after stimulation [II]. Total genes in each cluster is indicated in parentheses. (b) Centroid plot representing average kinetic profiles of the four clusters at the six measured time intervals. (c) Principal component analysis (PCA) of TFBS frequencies in the genomic sequences extracted from the 7,298 genes profiled in Figure Ia. (I 200 base pairs upstream and 200 base pairs down stream from the start of transcription). Prior to analysis, each gene was colorcoded by its respective cluster shown in Figure la (red = cluster/group I, no change, green = cluster/group 2 early elevated expression, blue = cluster/group 3, repressed expression, and yellow = cluster/group 4 late elevated expression). (d) The extracted promoter sequences of each gene were then compared with respect to TFBS composition alone by K-means clustering. Nine out of sixteen clusters contained more the 4 genes (indicated as groups $1,4,6,9,10,12,13,15$, and I6).

region or promoters of the pathway-influenced gene. Thus, we sought to ask whether this logic could be extended to tease out biologically significant associations between TFBS frequencies and kinetic patterns of gene expression from a previously published study of the human T-cell line Jurkat [11]. This microarray data set contains steady-state mRNA profiles measured at $0,1,2$,
6, 12 and 24 hours following stimulation. The data set was first filtered to remove uncharacterized and poorly annotated genes (see Methods). The hybridization data from the remaining 7,298 genes was then analyzed by Kmeans clustering to group or classify those genes with similar kinetic patterns of mitogen-induced expression (Figure 1a). As demonstrated in Figure 1b, the expression 
profiles of the 7,298 genes analyzed in phorbol ester and ionomycin stimulated Jurkat T-cells can be separated into 4 kinetic clusters.

The first cluster (group 1, red) was the largest (4539) and represented genes that were essentially unchanged by mitogen stimulation. The second cluster (group 2, green) contained 175 genes and represents genes whose expression was induced early, within the first 2 hours of stimulation. The third cluster (group 3, blue) contained 990 members and represents genes that were relatively repressed by mitogen stimulation. The fourth cluster (group 4, yellow) contained 1594 members and represents genes whose expression rose late (post 6 hours) following mitogen stimulation. Given the rather broad differences between the groups and the known mitogen and calcium sensitivity of the AP-1, NF-kappa B and NFAT transcription factors pathways, it was expected that many promoters of the induced gene clusters (particular group 2) would show an asymmetric enrichment for TFBSs that bind AP-1, NF-kappa B or NFAT [12]. To address this hypothesis, $1400 \mathrm{bp}$ of genomic sequence (1200 bp upstream and 200 bp downstream of the TSS) were extracted from the 7,298 genes using the ProSpector Promoter inspection tool (see Methods). These regions (referred to as promoter regions) were then scored for the presence of 164 different motifs based on the TRANSFAC 6.0 position weight matrices using the MatInspector algorithms described by Quandt et al [5]. Matrix and core thresholds were set at 0.75 and 1.0 respectively. The TFBS composition of the genes were then compared by principal component analysis (PCA), where the cluster classifications of the genes based on kinetic expression pattern were color coded $($ red $=$ cluster/group 1 ; green $=$ cluster/ group 2, blue = cluster/group 3, and yellow = cluster/ group 4$)$. The genes were then grouped by the relative promoter frequencies of the 164 motifs applying 0.75/1.0 matrix/core PWM thresholds. In this presentation, the original 164 PWM motif vector space of the genes is reduced to 3 principal component vectors each representing a summed linear contribution from all 164 motifs $[14,15]$. As shown in Figure 1c, the clustering of the promoter TFBS frequencies produces a diffuse pattern that shows no correlation with the kinetic categories derived from gene expression data in Figure 1b.

These data indicate that broad kinetic grouping by gene expression alone fails to show strong correlations with transcription factor binding site composition. Though dramatic, this conclusion is not unexpected. Recent studies suggest that the correlation between steady-state mRNA levels and active transcription is at best $50 \%$, since steady-state mRNA is the net result of not only nascent transcription, but also mRNA turnover [7]. Accordingly, promoter composition is likely to have a significantly stronger correlation with active transcription than with mRNA stability. Nonetheless, future studies aimed at generating a finer partitioning of the kinetic categories through the use of multiple conditions (e.g. different modes of stimulation) will be better prone to generate more selective gene groups with higher conditional correlation between TFBS composition and patterns of gene expression.

In clear contrast however, when the TFBS compositions of the 7,298 genes were analyzed independent of gene expression data by K-means clustering, sixteen distinct and stable clusters could be identified (Figure 1d). Seven of these clusters contained 4 or less genes and were discarded. The remaining 9 major partitions were composed of clusters containing from 271 (Cluster four) to 1266 (Cluster sixteen) genes (Figure 1d).

To determine whether there were any functional differences between the gene classes shown in Figure 1d, the genes in each cluster were analyzed for preferential enrichment or depletion of ontology terms using the GoMiner web-based software package [16]. GoMiner facilitates biological interpretation of gene lists using a quantitative statistical output that identifies gene ontology terms that are asymmetrically distributed between gene clusters. Overand under-represented terms are ranked by a two-sided $p$ value from the Fisher's exact T-test [16]. The top 40 gene ontology terms for each gene cluster are shown in Table One. On first inspection, it is clear that each of the 9 gene clusters have distinct differences in gene ontology terms. Cluster one appears dominated by cell cycle and DNA replication terms. The immune response, defense response and cell communication terms appear to be a major discriminating feature with prominent asymmetric distribution across the gene clusters. Development, morphogenesis and differentiation terms are also major class separating terms in the gene clusters.

To determine which TFBSs were most important for discriminating the different gene clusters, the 164 motifs were ranked for significance in each cluster by ANOVA assigned significance based on discriminatory power. The significance ranking was derived from the $p$-value output for each motif in each cluster and then converted to a color score based on the ranking (1-164 = low-high = blue-red). A contour heat diagram showing the differential ranking of the 164 motifs in each of the 9 clusters is shown in Figure 2a. As apparent from this heat diagram, the TFBS patterns of the majority of the clusters produce very distinct signatures (Figure $2 a$ ).

When the TFBS composition of the 7,298 promoter regions was scored using more stringent PWM thresholds optimized to yield fewer potential false positive 
Table I: Distribution of Ontology terms within Gene Clusters. The gene clusters identified in Figure Id were analyzed for asymmetric distribution of ontology terms using the Gominer Software [16]. The top 40 gene ontology terms for each cluster ranked by significance scoring (Fishers exact T-test) are shown. Total numbers of genes in each cluster are indicated in parentheses. Statistical ranking of asymmetrically distributed gene ontology terms is represented by an estimated p-value (Fisher's Exact T-test).

\begin{tabular}{|c|c|}
\hline & Cluster One (I I 87) \\
\hline P-Value & Ontology Term \\
\hline 0.0003 & DNA dependent DNA replication \\
\hline 0.0003 & mitotic cell cycle \\
\hline 0.0008 & DNA replication \\
\hline 0.001 & structural constituent of cytoskeleton \\
\hline 0.0014 & metabolism \\
\hline 0.0015 & proteolysis and peptidolysis \\
\hline 0.0016 & cell cycle \\
\hline 0.0016 & hydrolase activity \\
\hline 0.0016 & S phase of mitotic cell cycle \\
\hline 0.0021 & protein metabolism \\
\hline 0.0024 & protein catabolism \\
\hline 0.0028 & DNA replication and chromosome cycle \\
\hline 0.0029 & small ribosomal subunit \\
\hline 0.0031 & intracellular \\
\hline 0.0031 & extracellular \\
\hline 0.004 & DNA replication factor $\mathrm{C}$ complex \\
\hline 0.0059 & nucleic acid binding activity \\
\hline 0.0059 & ATP dependent helicase activity \\
\hline 0.006 & transmembrane receptor protein phosphatase activity \\
\hline 0.006 & transmembrane receptor protein tyrosine phosphatase activity \\
\hline 0.0061 & cell proliferation \\
\hline 0.0063 & mitochondrial inner membrane \\
\hline 0.0065 & extracellular space \\
\hline 0.0065 & macromolecule catabolism \\
\hline $0.007 \mid$ & protein phosphatase activity \\
\hline 0.0073 & nucleobase, nucleoside, nucleotide and nucleic acid metabolism \\
\hline 0.0074 & replication fork \\
\hline 0.0078 & protein amino acid dephosphorylation \\
\hline 0.0078 & dephosphorylation \\
\hline 0.0078 & protein-ligand dependent protein catabolism \\
\hline 0.0081 & mitochondrial ribosome \\
\hline 0.009 & inner membrane \\
\hline 0.0092 & mitochondrion \\
\hline 0.0095 & cellular_component unknown \\
\hline 0.0111 & helicase activity \\
\hline 0.0113 & organellar ribosome \\
\hline 0.0123 & N-linked glycosylation \\
\hline 0.0123 & di-, tri-valent inorganic cation homeostasis \\
\hline 0.014 & proton-transporting ATP synthase complex \\
\hline \multirow[t]{2}{*}{0.014} & spindle \\
\hline & Cluster Nine (724) \\
\hline P-Value & Ontology Term \\
\hline 0.0003 & mitochondrion \\
\hline 0.0005 & metabolism \\
\hline 0.0008 & intracellular \\
\hline 0.0018 & biosynthesis \\
\hline 0.0022 & complement activation, alternative pathway \\
\hline 0.003 & complement activation \\
\hline 0.0044 & complement activity \\
\hline 0.0047 & sugar binding activity \\
\hline 0.0047 & carbohydrate binding activity \\
\hline 0.006 & humoral defense mechanism (sensu Vertebrata) \\
\hline 0.0067 & plasma membrane \\
\hline 0.007 & cell adhesion molecule activity \\
\hline 0.0071 & I-phosphatidylinositol 3-kinase complex \\
\hline 0.0071 & membrane attack complex \\
\hline
\end{tabular}


Table I: Distribution of Ontology terms within Gene Clusters. The gene clusters identified in Figure Id were analyzed for asymmetric distribution of ontology terms using the Gominer Software [16]. The top $\mathbf{4 0}$ gene ontology terms for each cluster ranked by significance scoring (Fishers exact T-test) are shown. Total numbers of genes in each cluster are indicated in parentheses. Statistical ranking of asymmetrically distributed gene ontology terms is represented by an estimated $p$-value (Fisher's Exact T-test). (Continued)

\begin{tabular}{|c|c|}
\hline $0.007 \mid$ & hydrolase activity, acting on acid anhydrides, catalyzing transmembrane movement of substances \\
\hline 0.0071 & phosphatidylinositol 3-kinase activity \\
\hline 0.0079 & ATP-binding cassette $(A B C)$ transporter activity \\
\hline 0.0098 & cell adhesion \\
\hline 0.0099 & chemotaxis \\
\hline 0.0099 & taxis \\
\hline 0.0125 & cell-cell adhesion \\
\hline 0.013 & mitochondrial membrane \\
\hline 0.0151 & lectin \\
\hline 0.0156 & G-protein coupled receptor protein signaling pathway \\
\hline 0.0176 & cellular_component unknown \\
\hline 0.0187 & P-P-bond-hydrolysis-driven transporter activity \\
\hline 0.02 & thyroid hormone generation \\
\hline 0.02 & lipid raft \\
\hline 0.02 & ethanol oxidation \\
\hline 0.02 & ethanol metabolism \\
\hline 0.02 & flowering \\
\hline 0.02 & thyroid hormone metabolism \\
\hline 0.02 & aldo-keto reductase activity \\
\hline 0.02 & alcohol dehydrogenase activity, iron-dependent \\
\hline 0.02 & alcohol dehydrogenase activity, metal ion-independent \\
\hline 0.02 & T-cell differentiation \\
\hline 0.02 & negative regulation of $\mathrm{Wnt}$ receptor signaling pathway \\
\hline 0.02 & fluid secretion \\
\hline 0.022 & homophilic cell adhesion \\
\hline \multirow[t]{2}{*}{0.0266} & humoral immune response \\
\hline & Cluster Four (27I) \\
\hline P-Value & Ontology Term \\
\hline 0.0002 & cytoplasm \\
\hline 0.001 & transcription \\
\hline 0.0012 & regulation of transcription, DNA-dependent \\
\hline 0.0013 & regulation of transcription \\
\hline 0.0015 & transcription, DNA-dependent \\
\hline 0.0029 & immune response \\
\hline 0.0029 & nucleus \\
\hline 0.0034 & transferase activity, transferring sulfur-containing groups \\
\hline 0.0034 & solute:sodium symporter activity \\
\hline 0.005 & defense response \\
\hline 0.0051 & phenol metabolism \\
\hline 0.0051 & catecholamine metabolism \\
\hline 0.0051 & organic acid transporter activity \\
\hline 0.0053 & cell communication \\
\hline 0.0055 & response to biotic stimulus \\
\hline 0.0059 & protein modification \\
\hline 0.0063 & protein kinase CK2 activity \\
\hline 0.0069 & solute:cation symporter activity \\
\hline 0.0071 & response to external stimulus \\
\hline 0.0084 & negative regulation of transcription \\
\hline 0.0093 & biogenic amine metabolism \\
\hline 0.0093 & adherens junction \\
\hline 0.0096 & cAMP-dependent protein kinase activity \\
\hline 0.0096 & cyclic-nucleotide dependent protein kinase activity \\
\hline 0.0096 & casein kinase activity \\
\hline 0.0097 & transcription from Pol II promoter \\
\hline 0.0099 & secretin-like receptor activity \\
\hline 0.0099 & neurotransmitter:sodium symporter activity \\
\hline 0.0099 & neurotransmitter transporter activity \\
\hline 0.0099 & biogenic amine biosynthesis \\
\hline
\end{tabular}


Table I: Distribution of Ontology terms within Gene Clusters. The gene clusters identified in Figure Id were analyzed for asymmetric distribution of ontology terms using the Gominer Software [16]. The top 40 gene ontology terms for each cluster ranked by significance scoring (Fishers exact T-test) are shown. Total numbers of genes in each cluster are indicated in parentheses. Statistical ranking of asymmetrically distributed gene ontology terms is represented by an estimated $p$-value (Fisher's Exact T-test). (Continued)

\begin{tabular}{|c|c|}
\hline 0.0103 & protein amino acid phosphorylation \\
\hline 0.0106 & G-protein coupled receptor activity \\
\hline 0.0112 & neurogenesis \\
\hline 0.0119 & transmembrane receptor protein serine/threonine kinase signaling pathway \\
\hline 0.0128 & phosphorylation \\
\hline 0.0139 & small GTPase mediated signal transduction \\
\hline 0.0141 & protein kinase activity \\
\hline 0.0151 & brain development \\
\hline 0.016 & frizzled receptor signaling pathway \\
\hline \multirow[t]{2}{*}{0.016} & frizzled receptor activity \\
\hline & Cluster Ten (815) \\
\hline P-Value & Ontology Term \\
\hline$<.0001$ & nucleobase, nucleoside, nucleotide and nucleic acid metabolism \\
\hline$<.0001$ & nucleus \\
\hline$<.0001$ & intracellular \\
\hline$<.0001$ & extracellular space \\
\hline$<.0001$ & extracellular \\
\hline$<.0001$ & RNA binding activity \\
\hline$<.0001$ & nucleic acid binding activity \\
\hline 0.0001 & plasma glycoprotein \\
\hline 0.0001 & oxidoreductase activity, acting on the $\mathrm{CH}-\mathrm{NH} 2$ group of donors, oxygen as acceptor \\
\hline 0.0003 & oxidoreductase activity, acting on the $\mathrm{CH}-\mathrm{NH} 2$ group of donors \\
\hline 0.0003 & molecular_function \\
\hline 0.0003 & alpha-type channel activity \\
\hline 0.0004 & response to external stimulus \\
\hline 0.0004 & channel/pore class transporter activity \\
\hline 0.0005 & chymotrypsin activity \\
\hline 0.0005 & RNA metabolism \\
\hline 0.0007 & trypsin activity \\
\hline 0.0011 & metabolism \\
\hline 0.0014 & immune response \\
\hline 0.0015 & defense response \\
\hline 0.0016 & RNA processing \\
\hline 0.0025 & response to biotic stimulus \\
\hline 0.0028 & cell surface receptor linked signal transduction \\
\hline 0.0028 & integral to membrane \\
\hline 0.0031 & regulation of transcription \\
\hline 0.0032 & transcription \\
\hline 0.0037 & signal transducer activity \\
\hline 0.0039 & translation regulator activity \\
\hline 0.004 & regulation of transcription, DNA-dependent \\
\hline 0.004 & membrane \\
\hline 0.0042 & voltage-gated ion channel activity \\
\hline 0.0044 & ligand-dependent nuclear receptor activity \\
\hline 0.0044 & potassium channel activity \\
\hline 0.0044 & steroid hormone receptor activity \\
\hline 0.0045 & ion transport \\
\hline 0.005 & small GTPase mediated signal transduction \\
\hline 0.0051 & nucleoplasm \\
\hline 0.0052 & cation channel activity \\
\hline 0.0054 & digestion \\
\hline \multirow[t]{2}{*}{0.0058} & ligand-regulated transcription factor activity \\
\hline & Cluster Six (474) \\
\hline P-Value & Ontology Term \\
\hline 0.0002 & development \\
\hline 0.0002 & extracellular matrix structural constituent \\
\hline 0.0003 & muscle development \\
\hline
\end{tabular}


Table I: Distribution of Ontology terms within Gene Clusters. The gene clusters identified in Figure Id were analyzed for asymmetric distribution of ontology terms using the Gominer Software [16]. The top 40 gene ontology terms for each cluster ranked by significance scoring (Fishers exact T-test) are shown. Total numbers of genes in each cluster are indicated in parentheses. Statistical ranking of asymmetrically distributed gene ontology terms is represented by an estimated $p$-value (Fisher's Exact T-test). (Continued)

\begin{tabular}{|c|c|}
\hline 0.0004 & muscle contraction \\
\hline 0.0007 & intramolecular isomerase activity \\
\hline 0.0013 & cell differentiation \\
\hline 0.0014 & mitochondrion \\
\hline 0.002 & cellular process \\
\hline 0.002 & organogenesis \\
\hline 0.0022 & cell adhesion \\
\hline 0.0027 & cytoskeleton \\
\hline 0.0032 & oncogenesis \\
\hline 0.0032 & structural constituent of cytoskeleton \\
\hline 0.0033 & cell communication \\
\hline 0.0036 & morphogenesis \\
\hline 0.0037 & troponin complex \\
\hline 0.0037 & NGF/TNF (6 C-domain) receptor activity \\
\hline 0.0042 & circulation \\
\hline 0.0046 & structural molecule activity \\
\hline 0.0048 & actin cytoskeleton \\
\hline 0.0049 & cell motility \\
\hline 0.005 & muscle fiber \\
\hline 0.0056 & photoreceptor activity \\
\hline 0.0056 & G-protein coupled photoreceptor activity \\
\hline 0.0056 & collagen type I \\
\hline 0.011 & intermediate filament cytoskeleton \\
\hline 0.011 & intermediate filament \\
\hline 0.0125 & transcription cofactor activity \\
\hline 0.0128 & extracellular matrix structural constituent conferring tensile strength activity \\
\hline 0.0128 & sarcomere \\
\hline 0.0128 & myofibril \\
\hline 0.0128 & collagen \\
\hline 0.0139 & response to stress \\
\hline 0.0149 & hydrolase activity \\
\hline 0.016 & intramolecular isomerase activity, interconverting aldoses and ketoses \\
\hline 0.016 & phosphagen metabolism \\
\hline 0.016 & neurofilament \\
\hline 0.016 & galactose binding lectin \\
\hline 0.016 & inactivation of MAPK \\
\hline \multirow[t]{2}{*}{0.0176} & striated muscle thin filament \\
\hline & Cluster Twelve (619) \\
\hline P-Value & Ontology Term \\
\hline$<.0001$ & cell communication \\
\hline 0.0001 & signal transduction \\
\hline 0.0078 & development \\
\hline 0.0103 & phosphate metabolism \\
\hline 0.0103 & phosphorus metabolism \\
\hline 0.0159 & neurogenesis \\
\hline 0.016 & cell adhesion \\
\hline 0.0179 & intracellular signaling cascade \\
\hline 0.0196 & amino acid transport \\
\hline 0.0311 & small GTPase mediated signal transduction \\
\hline 0.0384 & coreceptor activity \\
\hline 0.0464 & heme-copper terminal oxidase activity \\
\hline 0.0464 & acute-phase response \\
\hline 0.0464 & regulation of metabolism \\
\hline 0.0476 & cell-cell signaling \\
\hline 0.085 & beta3-adrenergic receptor activity \\
\hline 0.085 & purine ribonucleoside catabolism \\
\hline 0.085 & purine ribonucleoside metabolism \\
\hline 0.085 & pentose catabolism \\
\hline
\end{tabular}


Table I: Distribution of Ontology terms within Gene Clusters. The gene clusters identified in Figure Id were analyzed for asymmetric distribution of ontology terms using the Gominer Software [16]. The top $\mathbf{4 0}$ gene ontology terms for each cluster ranked by significance scoring (Fishers exact T-test) are shown. Total numbers of genes in each cluster are indicated in parentheses. Statistical ranking of asymmetrically distributed gene ontology terms is represented by an estimated $p$-value (Fisher's Exact T-test). (Continued)

\begin{tabular}{|c|c|}
\hline 0.085 & pentose metabolism \\
\hline 0.085 & ribose catabolism \\
\hline 0.085 & adenosine metabolism \\
\hline 0.085 & manganese ion transport \\
\hline 0.085 & ADP-sugar diphosphatase activity \\
\hline 0.085 & bile acid biosynthesis \\
\hline 0.0858 & cellular respiration \\
\hline 0.094 & organelle organization and biogenesis \\
\hline 0.0966 & alcohol catabolism \\
\hline 0.1096 & xenobiotic metabolism \\
\hline 0.1096 & neuropeptide signaling pathway \\
\hline 0.1105 & meiosis \\
\hline 0.1136 & deaminase activity \\
\hline 0.1198 & synaptic transmission \\
\hline 0.1215 & transmission of nerve impulse \\
\hline 0.1314 & monovalent inorganic cation transporter activity \\
\hline 0.1491 & chloride transport \\
\hline 0.1627 & internalization receptor activity \\
\hline 0.1627 & regulation of mitotic cell cycle \\
\hline 0.1627 & cAMP metabolism \\
\hline \multirow[t]{2}{*}{0.1627} & regulation of cell volume \\
\hline & Cluster Thirteen (I208) \\
\hline P-Value & Ontology Term \\
\hline 0.0002 & mitochondrion \\
\hline 0.0004 & intracellular \\
\hline 0.0008 & metabolism \\
\hline 0.0012 & extracellular \\
\hline 0.0026 & DNA repair \\
\hline 0.0031 & immune response \\
\hline 0.0041 & extracellular space \\
\hline 0.0045 & phosphatidylinositol transporter activity \\
\hline 0.0061 & cytosolic large ribosomal subunit (sensu Eukarya) \\
\hline 0.0065 & defense response \\
\hline 0.0069 & nucleobase, nucleoside, nucleotide and nucleic acid metabolism \\
\hline 0.0071 & RNA binding activity \\
\hline 0.0078 & large ribosomal subunit \\
\hline 0.0083 & heme biosynthesis \\
\hline 0.0083 & sex determination \\
\hline 0.0095 & G-protein coupled receptor protein signaling pathway \\
\hline 0.0097 & integral to membrane \\
\hline 0.0098 & biosynthesis \\
\hline 0.0101 & integral to plasma membrane \\
\hline 0.0109 & mitotic cell cycle \\
\hline 0.0147 & pigment biosynthesis \\
\hline 0.0147 & post Golgi transport \\
\hline 0.015 & nucleus \\
\hline 0.0157 & cyclohydrolase activity \\
\hline 0.0157 & protein amino acid methylation \\
\hline 0.0157 & RNA-nucleus export \\
\hline 0.0157 & transferase activity, transferring pentosyl groups \\
\hline 0.0169 & porphyrin biosynthesis \\
\hline 0.0169 & chromatin remodeling complex \\
\hline 0.0169 & heme metabolism \\
\hline 0.0178 & plasma membrane \\
\hline 0.0192 & S phase of mitotic cell cycle \\
\hline 0.0193 & coenzymes and prosthetic group biosynthesis \\
\hline 0.0209 & cell surface receptor linked signal transduction \\
\hline 0.021 & ion transport \\
\hline
\end{tabular}


Table I: Distribution of Ontology terms within Gene Clusters. The gene clusters identified in Figure Id were analyzed for asymmetric distribution of ontology terms using the Gominer Software [16]. The top $\mathbf{4 0}$ gene ontology terms for each cluster ranked by significance scoring (Fishers exact T-test) are shown. Total numbers of genes in each cluster are indicated in parentheses. Statistical ranking of asymmetrically distributed gene ontology terms is represented by an estimated $p$-value (Fisher's Exact T-test). (Continued)

\begin{tabular}{|c|c|}
\hline 0.0233 & trypsin activity \\
\hline 0.0234 & pigment metabolism \\
\hline 0.0236 & inorganic anion transport \\
\hline 0.0266 & apoptosis regulator activity \\
\hline \multirow[t]{2}{*}{0.0268} & nucleic acid binding activity \\
\hline & Cluster Fifteen (725) \\
\hline P-Value & Ontology Term \\
\hline 0.0007 & blood vessel development \\
\hline 0.0007 & angiogenesis \\
\hline 0.001 & phosphotransferase activity, alcohol group as acceptor \\
\hline 0.0013 & nuclear localization sequence binding activity \\
\hline 0.0017 & protein kinase activity \\
\hline 0.002 & response to pest/pathogen/parasite \\
\hline 0.0023 & protein serine/threonine kinase activity \\
\hline 0.0024 & kinase activity \\
\hline 0.0025 & cellular process \\
\hline 0.0028 & cell migration \\
\hline 0.0038 & actin polymerization and/or depolymerization \\
\hline 0.0048 & spermatid development \\
\hline 0.0048 & NLS-bearing substrate-nucleus import \\
\hline 0.0048 & galactosyltransferase activity \\
\hline 0.0051 & signal transduction \\
\hline 0.0053 & protein tyrosine kinase activity \\
\hline 0.0059 & embryogenesis and morphogenesis \\
\hline 0.006 & neurogenesis \\
\hline 0.007 & immune response \\
\hline 0.0073 & cell-matrix adhesion \\
\hline 0.0073 & nucleotide binding activity \\
\hline 0.0077 & Golgi apparatus \\
\hline 0.0079 & transferase activity, transferring phosphorus-containing groups \\
\hline 0.0088 & phosphate metabolism \\
\hline 0.0088 & phosphorus metabolism \\
\hline 0.0091 & protein amino acid phosphorylation \\
\hline 0.0097 & response to wounding \\
\hline 0.0097 & response to biotic stimulus \\
\hline 0.0106 & phosphorylation \\
\hline 0.0111 & RAN protein binding activity \\
\hline 0.0112 & morphogenesis \\
\hline 0.0113 & development \\
\hline 0.0113 & purine nucleotide binding activity \\
\hline 0.012 & actin filament-based process \\
\hline 0.0121 & importin, beta-subunit \\
\hline 0.0121 & actin modulating activity \\
\hline 0.0121 & actin monomer binding activity \\
\hline 0.0121 & regulation of actin polymerization and/or depolymerization \\
\hline 0.0124 & cytoskeleton organization and biogenesis \\
\hline \multirow[t]{2}{*}{0.0137} & cell communication \\
\hline & Cluster Sixteen (1266) \\
\hline P-Value & Ontology Term \\
\hline 0.0004 & immune response \\
\hline 0.0008 & oncogenesis \\
\hline 0.0009 & defense response \\
\hline 0.0042 & ionic insulation of neurons by glial cells \\
\hline 0.0125 & inflammatory response \\
\hline 0.0245 & histogenesis and organogenesis \\
\hline 0.0261 & sarcomere alignment \\
\hline 0.0261 & phagocytosis, engulfment \\
\hline
\end{tabular}


predictions (Methods), a surprising decrease in the diversity of the clustering pattern for the promoters was observed (Figure 2b). The analysis predicted 6 clusters from which two were discarded for having fewer than 4 genes. As expected, a heat diagram of the 164 TFBS rankings in each of the clusters showed considerably less distinct signatures (Figure 2c). Moreover, the ontology terms associated with the 4 clusters were much less distinct with a higher total ratio of redundant terms (see supplemental data, Table two). This tendency for more relaxed PWM similarity thresholds to generate greater diversity in predicted promoter composition suggests that the inherent or "perceived" degenerate nature of transcription factor binding sites serves to broaden the potential "categories" or strategies of gene regulation [17]. This suggests high thresholds, though reducing the number of potential false positives, have the severe negative effect of overlooking real binding sites [17].
A logical prediction in this study is that the associated biological function of the transcription factors that regulate the gene groups should share some similarity with the function of the genes that they regulate. In other words, the "regulator" should show similar function to the "regulated". To ask this question, we looked for any correlation between the ontology terms of the transcription factors (TFs) predicted most likely to bind to the promoter regions of the gene clusters (TFO) and the ontology terms of the gene clusters themselves (GCO). Accordingly, a list of transcription factors known to recognize the most discriminating TFBSs for each cluster was generated (total of $55 \mathrm{TF}$ genes, Figures 3, 4, 5, 6, 7). The top 10 TFBSs were segregated into over-represented (RED) or under-represented (GREEN) groups for their respective gene clusters. The list of genes encoding the transcription factors that bind the top 10 TFBSs in each cluster was then compiled based on TRANSFAC 6.0 annotation. The GoMiner software was then used to rank the gene ontology terms based 
(a)

\section{(c)}

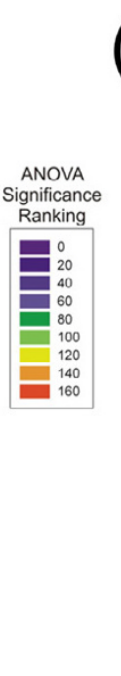

(b)

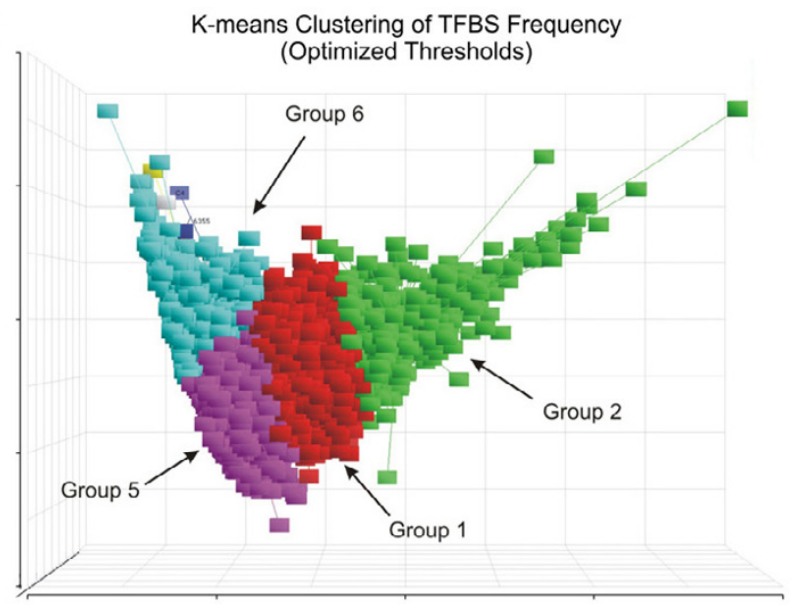

Promoter Clusters

Promoter Sequence Clustering of 7,298 Genes

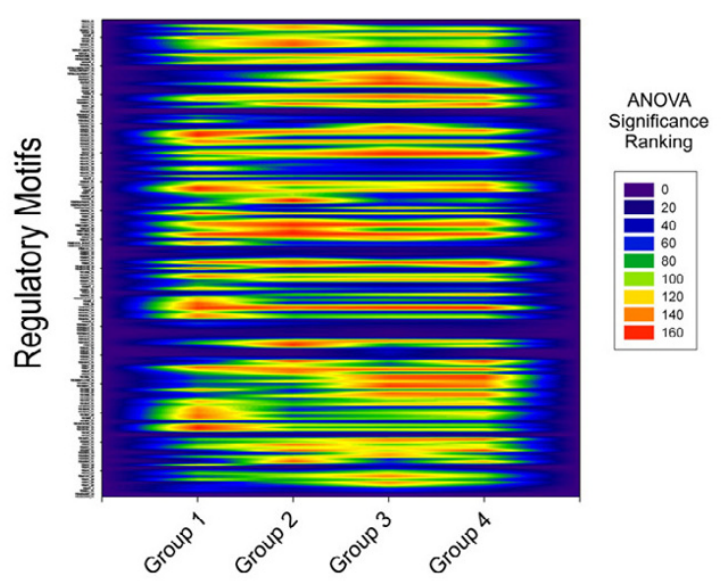

Optimized Threshold

\section{Figure 2}

Significance ranking of TFBSs in respective clusters. (a) The TFBSs in the sequences of each cluster were sorted and ranked by ANOVA analysis to determine those sites that best discriminated the different clusters. The TFBSs in each cluster were then assigned ranks (I-I64) according to their significance ( $p$-value) from the ANOVA analysis. Highest ranking in red, lowest in blue. (b) Partitioning of gene promoter composition with more stringent PWM matrix similarity thresholds reduces the number of clusters identified by K-means analysis. Shown are four of six clusters containing greater than 4 genes. (groups I, 2, 5 and 6). (c) Analysis of the most discriminating TFBSs in the four clusters in Figure $2 b$ by ANOVA, as in Figure $2 a$.

on the statistical significance of their occurrence within the transcription factor clusters (TFO). The top gene ontology terms with a ranking p-value less than 0.05 (determined by GoMiner) were then extracted and listed depending on whether they were over-represented (RED) or under-represented (GREEN) in each TFO. These lists were then compared with the top gene ontology terms of each respective gene cluster (gene cluster ontology, GCO) with $p$-values less then 0.05 . The over-represented transcription factor ontology terms (TFO) found to share similarity with terms in the respective gene cluster ontologies (GCO) (within two branches of the ontology clade) are displayed in bold capitals letters (Figures 3, 4, 5, 6, 7, right column). 


\section{Cluster One (top 20)}

\begin{tabular}{|c|c|}
\hline 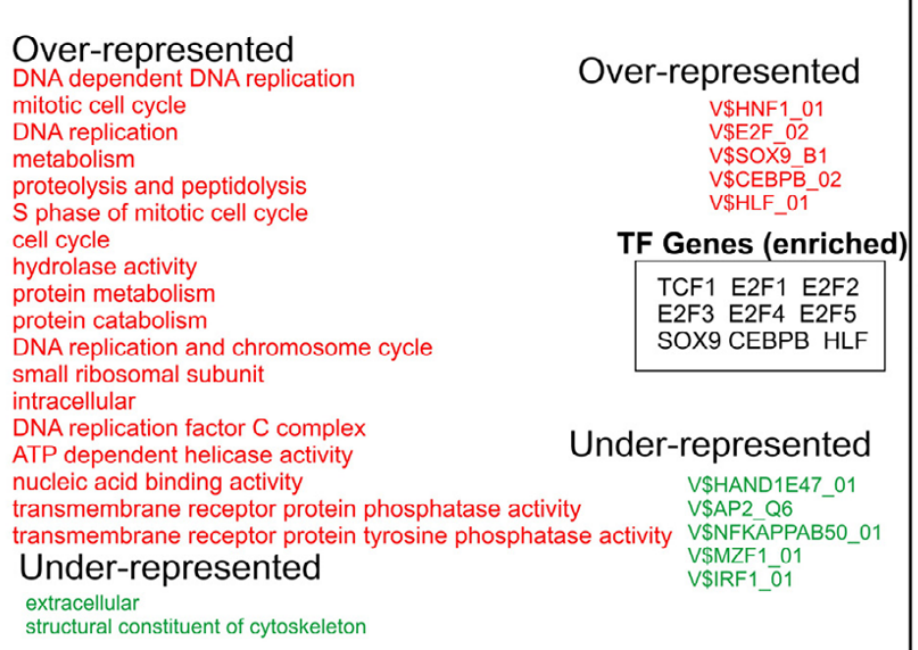 & $\begin{array}{l}\text { Over-represented } \quad \boldsymbol{p}=\mathbf{1 . 0 8 E - 0 4} \\
\text { REGULATION OF CELL PROLIFERATION } \\
\text { MITOTIC CELL CYCLE* } \\
\text { G1/S TRANSITION OF MITOTIC CELL CYCLE } \\
\text { REGULATION OF CELL CYCLE } \\
\text { CELL PROLIFERATION* } \\
\text { cellular physiological process } \\
\text { CELL CYCLE* } \\
\text { regulation of cellular process } \\
\text { apoptosis } \\
\text { Under-represented } \\
\text { cellular defense response } \\
\text { cellular defense response (sensu Vertebrata) } \\
\text { T-helper } 1 \text { type immune response } \\
\text { cell-mediated immune response } \\
\text { response to pest, pathogen or parasite } \\
\text { response to wounding } \\
\text { response to external biotic stimulus } \\
\text { positive regulation of protein biosynthesis } \\
\text { positive regulation of cytokine production }\end{array}$ \\
\hline $\begin{array}{l}\text { Ontology Terms } \\
\begin{array}{l}\text { (2085) } \\
{[113]} \\
\\
\text { Cluster Four (top 20) }\end{array}\end{array}$ & $\begin{array}{c}\text { TF Ontology Terms } \\
\text { (195) } \\
{[31]}\end{array}$ \\
\hline 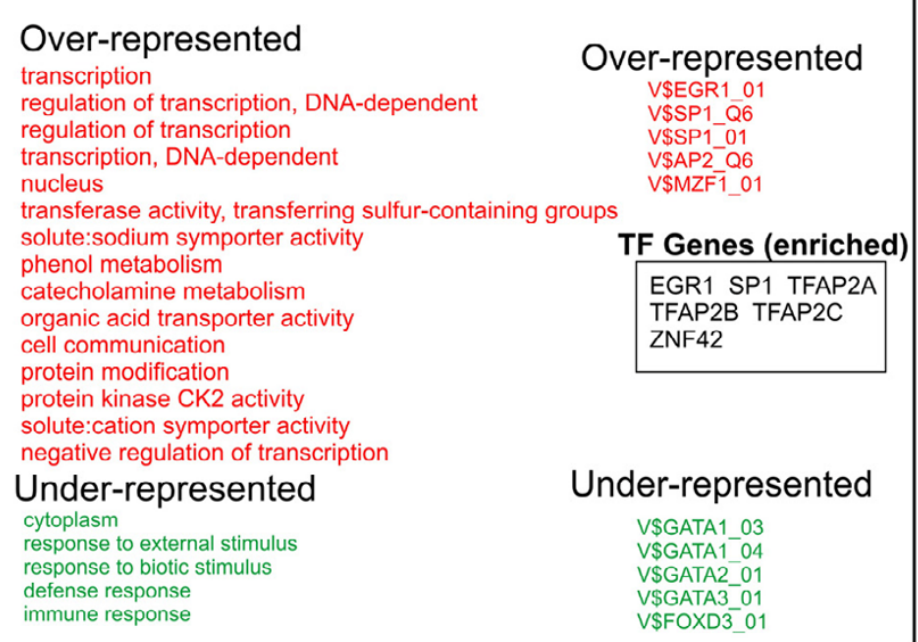 & $\begin{array}{l}\text { Over-represented } \mathbf{p}=\mathbf{0 . 3 0 1} \\
\text { transition metal ion binding } \\
\text { zinc ion binding }\end{array}$ \\
\hline $\begin{array}{l}\text { Ontology Terms } \\
\qquad \begin{array}{l}(696) \\
{[139]}\end{array}\end{array}$ & $\begin{array}{c}\text { TF Ontology Terms } \\
\text { (98) } \\
{[2]}\end{array}$ \\
\hline
\end{tabular}

Figure 3

Analysis of Ontology term distribution. The top 20 best discriminating gene ontology terms in each cluster were sorted for over-representation (RED) and under-representation (Green) and compared to the top 10 discriminating TFBSs for each cluster as determined by ANOVA (Figure 2). The top 10 over-represented (Red) and under-represented (Green) TFBSs for each cluster are shown. The transcription factors that recognize the TFBSs were grouped and then analyzed for asymmetric distribution of ontology terms using GoMiner (TF ontology terms, right). Transcription factor genes that are known to bind the over-represented TFBSs (TF Genes, enriched) are shown enclosed in boxes. Transcription factor ontology terms that overlap the gene cluster ontology terms within 2 branches of the ontology clade are shown in bold. Those terms with exact matches in the gene cluster ontologies are indicated with an asterisk. The numbers in parentheses indicate the total number of ontology terms associated with each respective cluster. The numbers in brackets indicated those ontology terms with a significance measurement $p$-value $<0.05$ (Fisher Exact T-test). Representative genes from Clusters one, six and thirteen are shown in supplemental Table 3. 


\section{Cluster Six (top 20)}

Over-represented
extracellular matrix structural constituent
development
muscle development
muscle contraction
intramolecular isomerase activity
cell differentiation
organogenesis
cellular process
cell adhesion
cytoskeleton
structural constituent of cytoskeleton
oncogenesis
cell communication
morphogenesis
troponin complex
NGF/TNF (6 C-domain) receptor activity
circulation
structural molecule activity
actin cytoskeleton
Under-represented
mitochondrion

Ontology Terms

(1032)

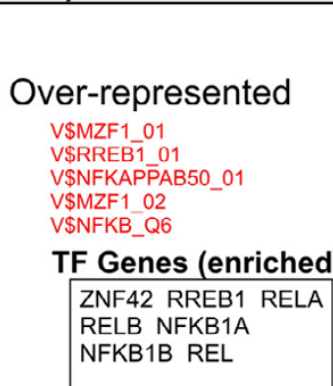

\section{Under-represented \\ V\$TATA_01 \\ V\$TATA C \\ V\$OCT1_03 \\ VSFREA $\bar{C} 701$ \\ V\$BRN2_01}

TF binding sites

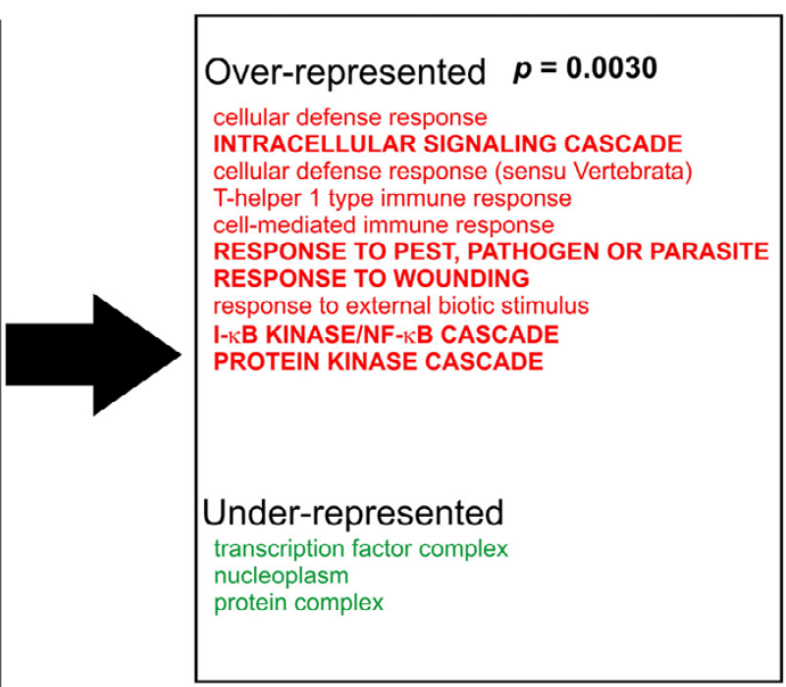

TF Ontology Terms

(141)

[35]

\section{Cluster Nine (top 20)}

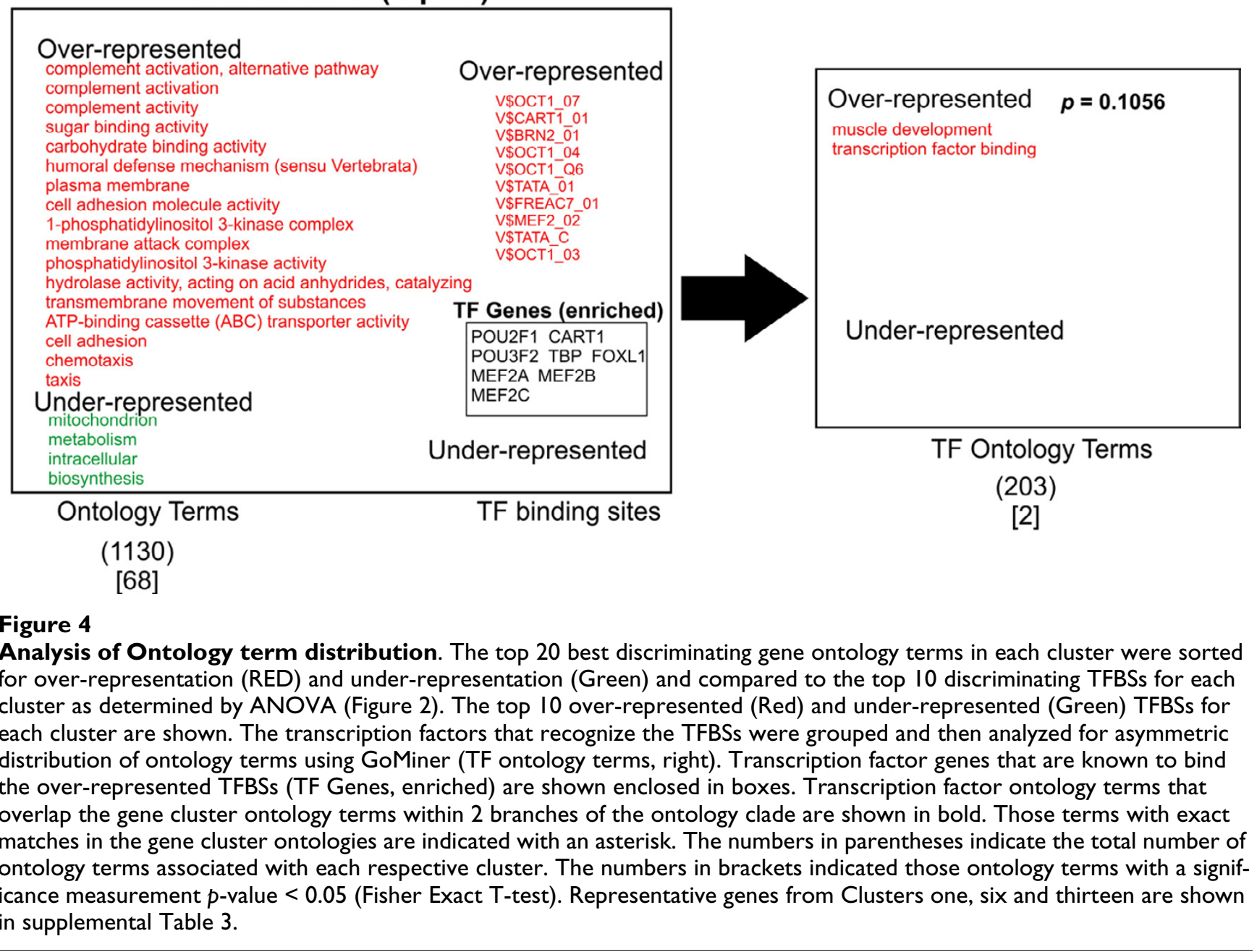




\section{Cluster Ten (top 20)}

Over-represented
extracellular
extracellular space
oxidoreductase activity, acting on the $\mathrm{CH}-\mathrm{NH} 2$
group of donors, oxygen as acceptor
plasma glycoprotein
oxidoreductase activity, acting on the $\mathrm{CH}-\mathrm{NH} 2$
group of donors
alpha-type channel activity
molecular_function
channel/pore class transporter activity
response to external stimulus
chymotrypsin activity
trypsin activity
immune response
defense response
Under-represented
intracellular
nucleic acid binding activity
nucleus
nucleobase, nucleoside, nucleotide and
nucleic acid metabolism
RNA binding activity
RNA metabolism

Ontology Terms (1344) [157]
Over-represented V\$HAND1E47_01 V\$MEIS1_01 V\$MYOD -26 V\$AREB 63 V\$AREB6_02

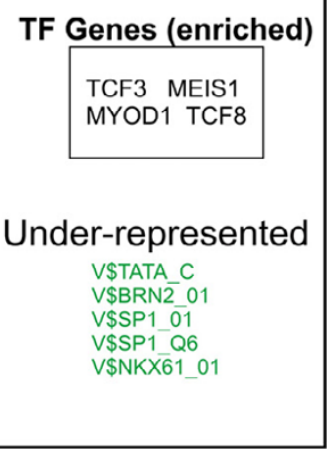

TF binding sites

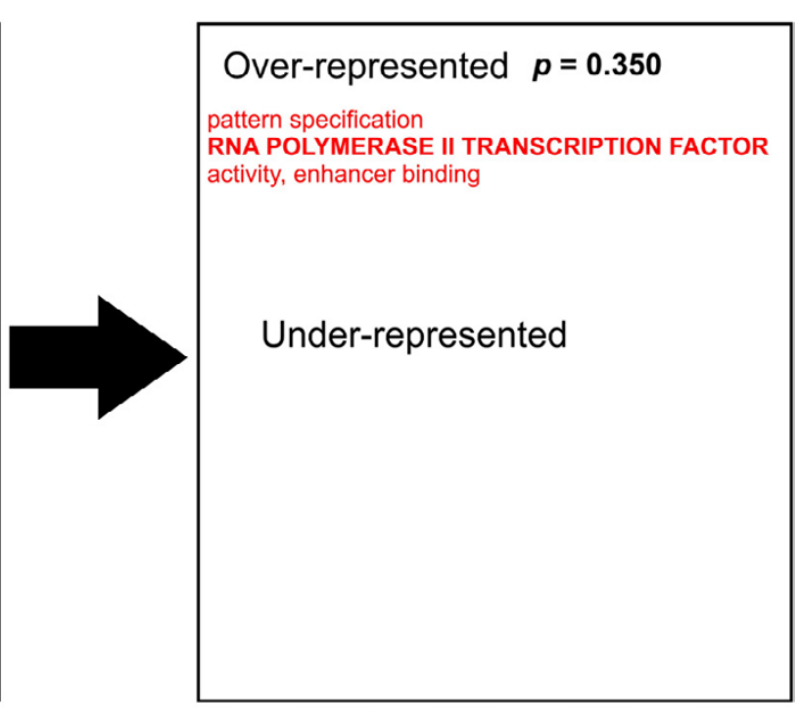

TF Ontology Terms

(114)

[2]

\footnotetext{
Cluster Twelve (top 20)

\begin{tabular}{|c|c|c|}
\hline $\begin{array}{l}\text { Over-represented } \\
\text { amino acid transport } \\
\text { coreceptor activity } \\
\text { heme-copper terminal oxidase activity } \\
\text { acute-phase response } \\
\text { regulation of metabolism } \\
\text { beta3-adrenergic receptor activity } \\
\text { purine ribonucleoside catabolism } \\
\text { purine ribonucleoside metabolism } \\
\text { pentose catabolism } \\
\text { pentose metabolism } \\
\text { Under-represented } \\
\text { cell communication } \\
\text { signal transduction } \\
\text { development } \\
\text { phosphate metabolism } \\
\text { phosphorus metabolism } \\
\text { neurogenesis } \\
\text { cell adhesion } \\
\text { intracellular signaling cascade } \\
\text { small GTPase mediated signal transduction } \\
\text { cell-cell signaling }\end{array}$ & $\begin{array}{l}\text { Under-represented } \\
\text { V\$SP1_01 } \\
\text { V\$AP2_Q6 } \\
\text { V\$NFKAPPAB50_01 } \\
\text { V\$SP1_Q6 } \\
\text { V\$MZF1_01 }\end{array}$ & $\begin{array}{l}\text { Over-represented } \mathbf{p = 0 . 4 9 5 0} \\
\text { integral to membrane } \\
\text { membrane } \\
\text { MUSCLE DEVELOPMENT } \\
\text { Golgi apparatus } \\
\text { endoplasmic reticulum } \\
\text { alcohol metabolism } \\
\text { sterol metabolism } \\
\text { cholesterol metabolism } \\
\text { steroid metabolism } \\
\text { transcription from Pol II promoter } \\
\text { biosynthesis } \\
\text { lipid metabolism } \\
\quad \text { Under-represented } \\
\text { cellular defense response } \\
\text { cellular defense response (sensu Vertebrata) } \\
\text { T-helper } 1 \text { type immune response } \\
\text { cell-mediated immune response } \\
\text { I-kB kinase/NF-kB cascade } \\
\text { protein kinase cascade } \\
\text { positive regulation of signal transduction } \\
\text { positive regulation of I-kB kinase/NF-kB cascade } \\
\text { regulation of I-kB kinase/NF-kB cascade }\end{array}$ \\
\hline $\begin{array}{l}\text { Ontology Terms } \\
\qquad \begin{array}{c}(172) \\
{[15]}\end{array}\end{array}$ & TF binding sites & TF Ontology Terms \\
\hline \multicolumn{3}{|c|}{$\begin{array}{l}\text { igure } 5 \\
\text { nalysis of Ontology term distribution. The top } 20 \text { best discriminating gene ontology terms in each cluster were sorted } \\
\text { r over-representation (RED) and under-representation (Green) and compared to the top } 10 \text { discriminating TFBSs for each } \\
\text { uster as determined by ANOVA (Figure } 2 \text { ). The top } 10 \text { over-represented (Red) and under-represented (Green) TFBSs for } \\
\text { ach cluster are shown. The transcription factors that recognize the TFBSs were grouped and then analyzed for asymmetric } \\
\text { stribution of ontology terms using GoMiner (TF ontology terms, right). Transcription factor genes that are known to bind } \\
\text { e over-represented TFBSs (TF Genes, enriched) are shown enclosed in boxes. Transcription factor ontology terms that } \\
\text { verlap the gene cluster ontology terms within } 2 \text { branches of the ontology clade are shown in bold. Those terms with exact } \\
\text { latches in the gene cluster ontologies are indicated with an asterisk. The numbers in parentheses indicate the total number of } \\
\text { ntology terms associated with each respective cluster. The numbers in brackets indicated those ontology terms with a signif- } \\
\text { ance measurement } p \text {-value }<0.05 \text { (Fisher Exact T-test). Representative genes from Clusters one, six and thirteen are shown } \\
\text { supplemental Table } 3 \text {. }\end{array}$} \\
\hline
\end{tabular}
}




\section{Cluster Thirteen (top 20)}

Over-represented
phosphatidylinositol transporter activity
heme biosynthesis
sex determination
cytosolic large ribosomal subunit (sensu Eukarya)
large ribosomal subunit
DNA repair
mitochondrion
mitotic cell cycle
RNA binding activity
biosynthesis
nucleobase, nucleoside, nucleotide
and nucleic acid metabolism
intracellular
metabolism
Under-represented
integral to membrane
extracellular space
extracellular
integral to plasma membrane
defense response
immune response
G-protein coupled receptor protein signaling pathway

\section{Ontology Terms}

(1759)

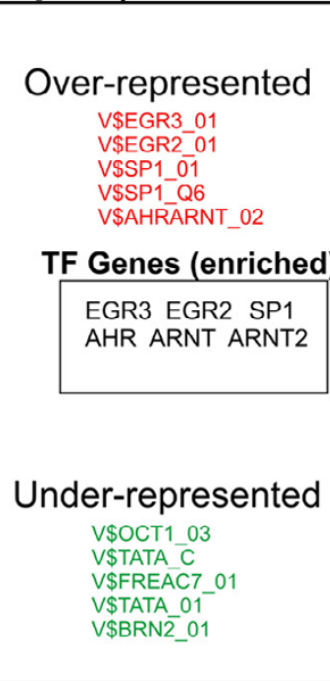

TF binding sites

[84]

\section{Cluster Fifteen (top 20)}

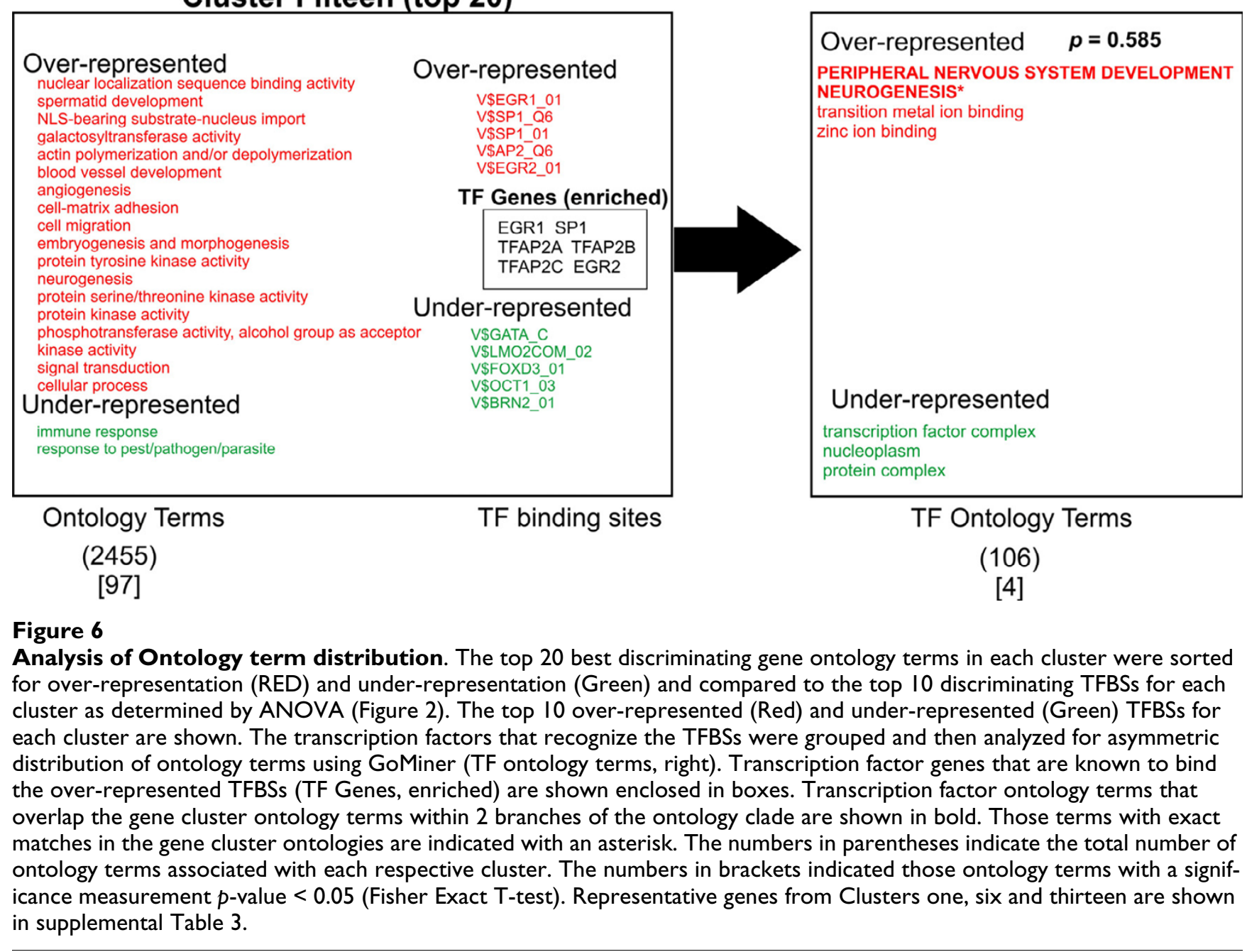




\section{Cluster Sixteen (top 20)}

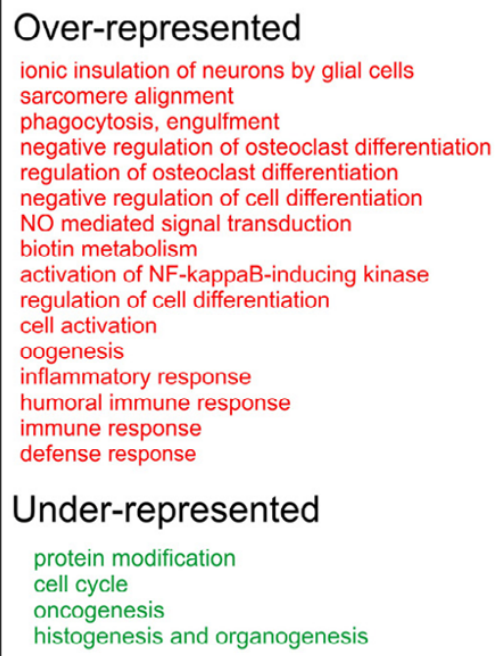

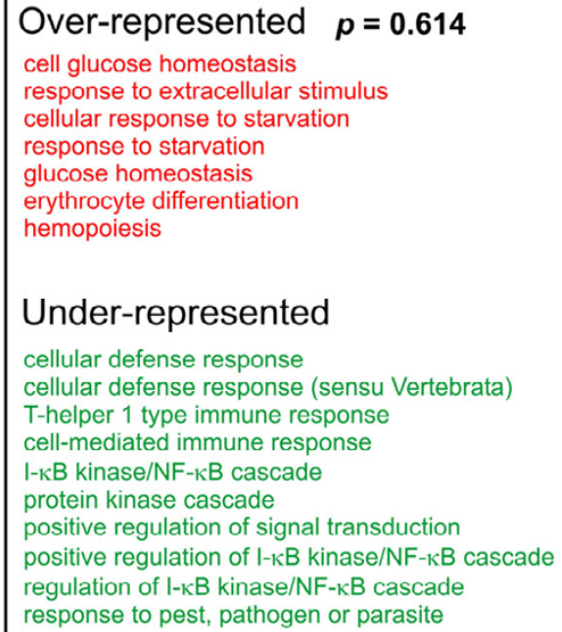

TF Ontology Terms

\section{Figure 7}

Analysis of Ontology term distribution. The top 20 best discriminating gene ontology terms in each cluster were sorted for over-representation (RED) and under-representation (Green) and compared to the top 10 discriminating TFBSs for each cluster as determined by ANOVA (Figure 2). The top 10 over-represented (Red) and under-represented (Green) TFBSs for each cluster are shown. The transcription factors that recognize the TFBSs were grouped and then analyzed for asymmetric distribution of ontology terms using GoMiner (TF ontology terms, right). Transcription factor genes that are known to bind the over-represented TFBSs (TF Genes, enriched) are shown enclosed in boxes. Transcription factor ontology terms that overlap the gene cluster ontology terms within 2 branches of the ontology clade are shown in bold. Those terms with exact matches in the gene cluster ontologies are indicated with an asterisk. The numbers in parentheses indicate the total number of ontology terms associated with each respective cluster. The numbers in brackets indicated those ontology terms with a significance measurement $p$-value $<0.05$ (Fisher Exact T-test). Representative genes from Clusters one, six and thirteen are shown in supplemental Table 3.

A qualitative comparison of the gene cluster ontology terms and their respective transcription factor ontology terms reveals several similarities in the over-represented terms. Cluster one shows significant overlap of ontology terms for cell division. Cluster six shows overlapping terms for cell communication. Cluster twelve contained overlapping terms for cellular metabolism. Cluster thirteen shows a puzzling anti-correlation with response to external stimuli. Cluster fifteen shows overlapping terms with morphogenesis and development. When these correlations are tested for significance by the method of hypergeometric distribution, Clusters one and six shows statistically significant correlation. Within Cluster one, gene cluster and transcription factor ontology terms for cell cycle regulation overlapped significantly $(p=1.08 \mathrm{E}-04)$. Within Cluster six, there was substantial overlap for cell communication ontology terms $(p=0.0030)$. Both cell cycle regulation and cell communication encompass fundamental and highly conserved processes in mammalian cells. Less than a third of clusters showed statistically significant correlations between gene group and transcription factor ontology terms. Nonetheless, given the unbiased manner in the which the gene lists and TF lists were generated and the small number of TF genes used to generate that TFO terms (55) compared to the number used to generate the GCO terms (7298), this approach shows substantial promise for identifying functional correlations between the transcriptional pathways and the genes regulated by them. It is reasonable to anticipate that these correlations will strengthen as the number and quality of the PWMs expand and the transcription factor gene ontology annotation improves in number and accuracy (see Discussion).

\section{Discussion}

Changes or alteration in gene expression are often linked to influences at the regulatory elements within the promoter regions of the targeted genes. The transcription 
factors that bind these regulatory elements form the final controlling functional link to the signaling pathways that are triggered and integrated as the cell adapts to environmental change. Thus, collective control of these integrated pathways forms the major conduit that governs changes and patterns of cellular behavior. These relationships are particularly applicable to metazoan systems.

Transcriptional control in metazoan cells is the culmination of multiple signal-induced transcriptional pathways, where the collective influence of more than one transcription factor and pathway hold sway on the ultimate expression of targeted genes. This combinatorial logic provides a means through which a finite number of transcriptional pathways can converge to produce seemingly infinite patterns of gene regulatory control. Deciphering this logic and how it links downstream function to upstream signaling requires expanded methods of interpreting promoter composition. By classifying patterns of promoter composition and linking these classifications to functional categories, of both the regulated genes and the transcription factors that regulate them, this approach provides a rational method for identifying meaningful relationships between promoter composition and gene function.

Though only 2 of 9 clusters showed a statistically significant correlation between ontology terms of the clusters and the transcription factors (Figures 3, 4, 5, 6, 7), an inspection of the ontology terms of several of the gene clusters in comparison to the transcription factors reveals numerous relationships that have been well established in the literature, though not reflected in the currently available ontological annotation for the factors. Cluster one is dominated by E2F transcription factors that are well known to exert control over genes involved in cell cycle regulation. Therefore, the overlap between Cluster one gene and transcription factor ontology terms for cell cycle regulation are significant ( $p$-value $=1.08 \mathrm{E}-04)$. Cluster Four showed no matches in the most significant ontology terms, however, the significant potential regulators of this cluster include AP-2 transcription factors, which have broad roles in vertebrate development including control of apoptosis and cell cycle [18]. Moreover, AP-2 factors have been also found to control receptor tyrosine kinase expression and other factors involved in the negative regulation of gene expression $[19,20]$. EGR1 and ZNF42 factors are widely known to regulate genes important for mitogenesis and differentiation [21-23]. Thus, a more expanded annotation of these terms would have shown greater correlation with the top ontology terms in both Cluster four and Cluster fifteen. These include cell communication, negative regulation of transcription, protein modification, protein tyrosine kinase activity, embryogenesis, morphogenesis, signal transduction and angiogenesis (Figures 3 and 6). Even though Cluster six shows statistically significant overlap between its ontology terms and those of its potential regulating transcription factors, many seemingly obvious matches could not be found in the annotation of some of the potential regulators. In particular, there is a significant absence of ontology terms for oncogenesis, morphogenesis and cellular differentiation for the NF-kappa B family subset of the top discriminating transcription factors. Control of these cellular process are well described for NF-kappa B [24]. The transcription factors in Cluster nine show no overlap; yet, it is dominated by octamer binding sites and several reports indicate octamer family members have a role in the control of expression of cellular adhesion molecules and other participants in wound healing $[25,26]$. In Cluster ten, the roles for TCF3 and TCF8 in early B-cell differentiation, immunoglobin expression and T-cell function certainly should have produced an overlap with the gene cluster ontology terms for immune response and defense response [27-29].

Another dominant factor that will improve the deduced linkages between ontologies of the regulating transcription factors and the regulated genes will be improvements in the accuracy of predicting TFBS occurrence. Multiple difficult factors have to be addressed. The first is accurate prediction of the promoter regions themselves. In this work, we define the promoter region in terms of the start of transcription (TSS) and retrieve sequence 200 bp downstream and $1200 \mathrm{bp}$ upstream of this position. Using the ProSpector search engine, the TSS is extracted from RefSeq annotation provided by the USCS genome assembly [30] http://genome.ucsc.edu. More precise identification of TSS is available from recent curated databases containing empirically derived TSS positions such as MPromDb http://bioinformatics.med.ohio-state.edu/MPromDb/,

OMGProm http://bioinformatics.med.ohio-state.edu/ OMGProm/, and DBTSS http://dbtss.hgc.jp/[31,32]. These resources will certainly improve on the accuracy of the promoter identification as their inventories continue to grow from the current 8,793 (DBTSS) and 13,780 (MPromDb) human genes. Nonetheless, a comparison of the promoter sequences queried from ProSpector and those from MPromDb showed a greater than $80 \%$ overlap in more than $80 \%$ of the mutually retrieved sequences (data not shown). It should be noted that metazoan promoter regions are highly complex and have multiple different TSS positions and consequently multiple promoters [33]. Many of these alternate promoters are tissue specific [33]. This feature unavoidably confounds the approach and is not adequately addressed in current promoter analysis tools. In addition to alternate promoters, metazoan gene regulatory regions are influenced by distant enhancer regions, locus control regions and a complicated tissue-specific interplay between 
transcriptional co-activator complexes and transcription factors [1,34-36]. These complex factors probably account for the better performance of promoter prediction tools on yeast data sets in comparison to higher eukaryotes [37].

A particularly difficult problem with the use of PWMs to annotate gene regulatory regions is the unavoidable occurrence of "false positive" and "false negatives". This is predominantly the case when searching for new TFBSs in uncharacterized genetic regions. Figures $2 b$ and $2 c$ show that using a high PWM threshold has the negative result of reduced promoter discrimination and potentially high levels of true "false negatives". At the heart of the matter is how we discriminate true false negatives and positives. It is indisputable that this can only be done through empirical validation and verification. The thresholds set for the PWM analysis in figures $2 \mathrm{~b}$ and $2 \mathrm{c}$ were too high to detect known sites for CREB, AP1, NF-kappa B and NFAT in the IL2 promoter and failed to retrieve any of the 5 known sites for NFAT in the IL4 promoter [38-43]. Thus, the use of high thresholds is inappropriate. For empirically uncharacterized gene regulatory regions, there is no way to discriminate between correct identifications, true false positives or false negatives. High frequency occurrence of motifs in some promoters should be met with some skepticism, but it is important to keep in mind that our understanding of transcription factor interaction with the genome continues to evolve. The interaction between transcription factors and TFBSs is not static, but highly dynamic and repetitive [44]. Thus, gradients of high and low affinity binding sites for classes of factors within a single gene regulatory locus could be physiologically relevant.

The presence of GC rich regions and CpG islands creates an important issue that requires consideration. These types of regions contain high densities of binding sites for factors such as Sp1, AP2, and EGR2/3. Though greater than $80 \%$ of promoters of are thought to contain CpG islands [45,46], differences in their presence, length or position will lead to background noise in the analysis. Recently developed approaches are able to address this problem through the use of background models representing either the entire genome (which is still subject to GC rich asymmetry because of the preferential concentration at transcription start sites) or random/unselected groups of promoter regions $[47,48]$. The method described in this current study ranks motifs not by their PWM score, but by using ANOVA to discriminate across the opposing clusters. By this approach, the aggregate of the opposing clusters serves as the background model for discriminatory significance of the TFBSs within each group. Though the presence of GC rich regions contribute significant noise to the analysis, this problem does not overwhelm the approach since it robustly discriminates true differences in promoter composition and correctly groups genes of known ontology with those containing mutual TFBSs that have been empirically validated (see supplemental Table 3).

Only Clusters fifteen, thirteen and four show high ranks for GC-containing TFBSs (Figures 3 and 6). At the very least, this indicates that there is a non-random distribution of GC rich regions amongst promoters. Nonetheless, the relative contribution of GC rich tracts or $\mathrm{CpG}$ islands to this distribution cannot be determined by our method. As expected, the clusters with high ranks for GC-containing TFBSs are in close apposition (Figure 1d). The fact that they show rather low correlation between GCO and TFO reflects the noise due to the high occurrence of GC rich regions. Still, it must be emphasized that $\mathrm{CpG}$ islands represent legitimate sites for factors like Sp1, EGR3/2 and AP2. Thus, the detection of such binding sites is likely to be physiologically important and their clustering patterns may contain biological information that will increase in importance as our understanding of transcription factor ontology is refined. Interestingly, recent studies suggest that genes lacking CpG islands tend to be expressed with a higher degree of tissue specificity and contain more GO terms consistent with "signal transducer", confirming the speculation that many CpG islands are associated with house-keeping gene function [46].

Unlike the yeast studies of Tavazoie et al [49], our approach failed to show any correlation between gene expression patterns at the RNA level and promoter TFBS composition. This result could be due in large part to the differences in yeast and metazoan gene regulatory regions as discussed above. In addition, post-transcriptional regulation of RNA stability is likely to be much more complex in metazoans than yeast. Another very important consideration is that Tavazoie et al chose to study the cell cycle, a time series of cellular behavior that is rich in various distinct molecular programs. It may be that the use of time-dependent changes following mitogen stimulation is too broad and lacks sufficient variability and distinction of gene expression to provide the discriminatory power necessary for the analysis of gene regulatory regions. Recently, another group has made an elegant application of GO terms to predict biological function by promoter composition [50]. By this approach, Bluthgen et al used predetermined TFBS combinations of known biological significance to extract genes with similar biological function based on overlapping promoter composition. This approach is very promising, confirms our central hypothesis, and shares similarity with a previously reported method where the biological significance of TFBS combinations, derived from kinetic profiles of transcriptional regulator occupancy via chromatin immuno-precipita- 
tion, was used to identify similarly regulated genes [14]. Our analysis differs from Bluthgen et al in that it does not depend on prior knowledge. In contrast, it begins with neither a pre-selected TFBS framework nor any other biological information. The possibility of identifying previously unrecognized ontologies linking the targeted genes with their targeting transcription factors remains preserved.

\section{Conclusion}

The examination of the upstream regulatory sequences of eukaryotic genes has the potential of yielding a wealth of information that will unravel the transcriptional control codes that govern spatial and temporal changes in gene expression. Combining multivariate analysis of promoter composition with classification by gene ontology provides a method that defines functional links between regulated genes and the genes that regulate them. The above are just a few of the examples where expanded ontology term annotation for the transcription factors based on current literature and improved promoter annotation methods will enhance the functional correlation between the regulator and the regulated. Just as important, these examples also point out how this method may also aid in identifying previously unrecognized functions for known transcription factors through the identification of "mutual ontology" terms. Ultimately, it will be the broader refinement and expansion of both PWMs for TFBSs and the functional vocabulary for all genes (in particular those gene encoding transcription factors), that will have a significant impact on improving the utility of this approach.

\section{Methods}

ProSpector database

To aid in the extraction and analysis of human promoter regions, a web-based resource named ProSpector (PROmoter inSPECTion) was developed [51]. The ProSpector website operates through an Apache web server and a MySQL relational database. The user interface of the website is written in PHP. The website provides a search tool for retrieving oriented human gene promoter regions by gene name (HUGO), gene description, gene symbol (HUGO), UniGene cluster, RefSeq ID, or LocusLink ID. The search feature is facilitated by keeping local copies of NCBI databases, including UniGene, RefSeq, and LocusLink. The actual promoter sequences are retrieved through a tool developed by the Genome Analysis Unit of the National Cancer Institute [52]. This tool retrieves promoters by extracting regions $5^{\prime}$ of gene transcription start sites identified by RefSeq annotation. Transcription start is defined by RefSeq mRNAs aligned with genomic chromosomal contigs from the UCSC/NCBI Assembly - hg12/ Build 30. ProSpector also allows extracted promoters to be analyzed for putative transcription factor binding sites using the MatInspector algorithms described by Quandt et al [5] and a subset of the position weight matrices (PWM) from the TRANSFAC 6.0 public database of transcription factors [53]. Briefly, base composition at putative TFBS is calculated as a vector score $\left(C_{i}(i)\right)$ where:

$C_{i}(i)=(100 / \ln 5) \times\left[\sum_{b \in A, C, G, T, g a p}[P(i, b) \times \ln P(i, b)]+\ln 5\right]$

$\mathrm{P}(i, \mathrm{~b})$ being the relative frequency of base $(b)$ at position (i) calculated from the PWM. Core similarity is used to quickly screen for potential binding sites with a high similarity to the most conserved region of the PWM and is determined from the four consecutive bases in the PWM with the highest $\mathrm{Ci}$ and calculated using:

$$
\begin{aligned}
& \text { core_sim }=\left[\sum_{j=m}^{m+3} \operatorname{score}(b, j)\right] /\left[\sum_{j=m}^{m+3} \text { max_score }(j)\right] \\
& 0 \leq \text { core_sim } \leq 1
\end{aligned}
$$

The score for base $(b)$ and position $(j)$ is simply the matrix value of base $(b)$ at position $(j)$ as defined by the PWM and the max score is the highest value in the matrix at position $(j)$. Likeness or similarity to the TFBS PWM is calculated independent of the core by:

$$
\begin{aligned}
& \text { mat_sim }=\left[\sum_{j=1}^{n} C_{i}(j) \times \operatorname{score}(b, j)\right] /\left[\sum_{j=1}^{n} C_{i}(j) \times \text { max_score }(j)\right] \\
& 0 \leq \text { mat_sim } \leq 1
\end{aligned}
$$

A subset of 164 PWMs representative of the major families of human transcription factors contained in TRANSFAC 6.0 was employed in this study.

\section{Optimization of TRANSFAC thresholds}

When promoter sequences are analyzed for potential transcription factor binding sites, they are selected based on their similarity to TRANSFAC position weight matrices. This similarity is represented by its matrix similarity (mat_sim, Equation 3). By setting a threshold, only potential binding sites with an equal or larger similarity are selected. Because each position weight matrix is of differing inherent degeneracy, an optimized matrix threshold was generated for each matrix to provide an alternative method to minimize the number of potential false positive binding sites. To optimize the matrix thresholds, 1,000,000 bases of random sequence were analyzed with each matrix at intervals of successively higher matrix thresholds. The optimum threshold was arbitrarily defined for each matrix to be the point at which the matrix was detected as scoring only one binding site per $1000 \mathrm{bp}$ of the random DNA. 


\section{Microarray analysis}

Analysis was performed on previously published microarray data [11] to generate a list of genes separated into groups based on specific steady-state mRNA expression levels. In these studies, the Jurkat human T-cell line was stimulated with phorbol ester and ionomycin. mRNA was isolated from cells at $0,1,2,6,12$, and 24 hours after stimulation. The prefiltered hybridization signals (provided by Dieh et al [11]) were normalized and filtered to remove any spots marked as "bad" on any of the twelve arrays. The ratio expression data was then log transformed and standardized to a control set of hybridization signals from mRNA isolated from untreated Jurkat T-cells at each time point. The promoter regions (defined as $1200 \mathrm{bp}$ upstream and $200 \mathrm{bp}$ downstream from the transcription start site) of the resulting list of Unigene clusters were then retrieved using the ProSpector website. UniGene clusters for which no sequence could be found were discarded in this step. A final list of 7298 UniGene clusters and promoter regions remained. For analysis of gene expression data, the method of K-means clustering was used [54]. The optimum number of clusters for the data set (four) was determined using the method described by Davies and Bouldin [55].

\section{Promoter analysis}

The genes analyzed in the microarray analysis were also analyzed for putative transcription factor binding using the ProSpector website http://prospector.nci.nih.gov. The gene promoter regions spanning $1200 \mathrm{bp}$ upstream of transcription start and 200 bp downstream of transcription start were analyzed with all 164 position weight matrices. The analysis was performed twice: once applying a common matrix threshold of 0.75 and again with the optimized matrix thresholds. In both analyses, a threshold of 1 for the core similarity was used. The results of the analysis were analyzed by segregating the genes based on the number of each position weight matrix that scored a binding site in the promoter. As in the microarray analysis, the method of Davies and Bouldin was used to determine the optimal number of clusters according to promoter composition. K-means clustering was used to segregate the genes. In the analysis with a blanket 0.75 matrix threshold, the data was found through DaviesBouldin analysis to separate into 16 groups. These clusters remained stable after the introduction of normalized Gaussian noise up to two fold standard deviation. Seven of the groups were small, containing 1 to 4 genes, and were discarded as outliers. The final result was 9 groups. The analysis was also conducted using optimized thresholds (see above). This analysis segregated into 6 groups. Again, groups with 4 or less genes were discarded as outliers leaving 4 groups derived from the optimized threshold TFBS analysis. For each analysis, clustered genes were analyzed using ANOVA to determine the transcription fac- tor binding site motifs most significant in differentiating the clusters. Principal component analysis (PCA), ANOVA (one-way) and K-means clustering analysis were performed using Partek Pro 5.0 (Partek Corp.).

\section{Gene ontology}

The GoMiner gene ontology tool was used to rank and categorize the gene ontology terms that were more significantly enriched beyond random assignment in each gene cluster [16]. Gene ontology terms were ranked according to $p$-values (Fisher's Exact T-test) generated by GoMiner [16]. Testing comparing ten random gene groups (1000 each) showed only random grouping of ontology terms versus the total population (data not shown). GoMiner was also used to identify those ontology terms that were enriched in the genes groups encoding the transcription factors known to associate with the most significant TFBSs identified in each respective cluster by ANOVA analysis. Significance testing for shared gene cluster ontology (GCO) terms and transcription factor ontology (TFO) terms was done by estimating the random probability of observing significant ontology terms in both TFO and GCO. The number of TFO terms were considered to be N, of which $\mathrm{n}$ are significant, and there are $\mathrm{m}$ significant GCO's found in TFO list of which $k$ are also significant TFO's. The probability of obtaining k terms was tested if $n$ values are randomly drawn from all TFO terms in which $\mathrm{m}$ are GCO's. The random process describing the nullhypothesis (no preferential overlap of GO terms) is described by the hypergeometric distribution which can be calculated by the phyper function of the R-Statistical software [56].

\section{Implementation}

The ProSpector promoter retrieval and annotation tool is available for open access at http://prospector.nci.nih.gov. ProSpector is compatible with Internet Explorer, Mozilla, Firefox, Opera and Safari.

\section{Authors' contributions}

MCM conceived of, designed, and implemented the ProSpector promoter annotation tool, carried out the promoter and ontology term analysis and assisted in the drafting of the manuscript. RT carried out statistics, promoter and ontology term analysis and assisted in the drafting of the manuscript. WC, IC, WJF, IM and CMH provided advice and assisted in the preparation of the manuscript. GVRC provided advice and performed much of the statistical analysis. KG conceived of the project, provided advice and opinions essential to the development of the analysis and helped draft the manuscript. All authors read and approved the final manuscript. 


\section{Additional material}

\section{Additional file 1 \\ Supplemental Table 2, ontology terms associated with the 4 clusters in Fig- ure 2 \\ Click here for file \\ [http://www.biomedcentral.com/content/supplementary/1471- 2105-6-259-S1.pdf]}

\section{Additional file 2}

Supplemental Table 3, representative genes from Clusters one, six and thirteen

Click here for file

[http://www.biomedcentral.com/content/supplementary/14712105-6-259-S2.pdf]

\section{Acknowledgements}

This research was supported by the Intramural Research Program of the $\mathrm{NIH}$, National Cancer Institute.

\section{References}

I. Michelson AM: Deciphering genetic regulatory codes: a challenge for functional genomics. Proc Natl Acad Sci U S A 2002, 99:546-548.

2. Harbison CT, Gordon DB, Lee TI, Rinaldi NJ, Macisaac KD, Danford TW, Hannett NM, Tagne JB, Reynolds DB, Yoo J, Jennings EG, Zeitlinger J, Pokholok DK, Kellis M, Rolfe PA, Takusagawa KT, Lander ES, Gifford DK, Fraenkel E, Young RA: Transcriptional regulatory code of a eukaryotic genome. Nature 2004, 431 :99-104.

3. Liu Y, Wei L, Batzoglou S, Brutlag DL, Liu JS, Liu XS: A suite of webbased programs to search for transcriptional regulatory motifs. Nucleic Acids Res 2004, 32:W204-W207.

4. Liu XS, Brutlag DL, Liu JS: An algorithm for finding protein-DNA binding sites with applications to chromatin-immunoprecipitation microarray experiments. Nat Biotechnol 2002, 20:835-839.

5. Quandt K, Frech K, Karas H, Wingender E, Werner T: Matlnd and Matinspector: new fast and versatile tools for detection of consensus matches in nucleotide sequence data. Nucleic Acids Res 1995, 23:4878-4884.

6. Hochheimer A, Tjian R: Diversified transcription initiation complexes expand promoter selectivity and tissue-specific gene expression. Genes Dev 2003, I 7: I309-1320.

7. Fan J, Yang X, Wang W, Wood WHIII, Becker KG, Gorospe M: Global analysis of stress-regulated mRNA turnover by using cDNA arrays. Proc Natl Acad Sci U S A 2002, 99: 106 I I-106 I6.

8. Schones DE, Sumazin $P$, Zhang MQ: Similarity of position frequency matrices for transcription factor binding sites. Bioinformatics 2005, 21:307-313.

9. Harris MA, Clark J, Ireland A, Lomax J, Ashburner M, Foulger R, Eilbeck K, Lewis S, Marshall B, Mungall C, Richter J, Rubin GM, Blake JA, Bult C, Dolan M, Drabkin H, Eppig JT, Hill DP, Ni L, Ringwald M, Balakrishnan R, Cherry JM, Christie KR, Costanzo MC, Dwight SS, Engel S, Fisk DG, Hirschman JE, Hong EL, Nash RS, Sethuraman A, Theesfeld CL, Botstein D, Dolinski K, Feierbach B, Berardini T, Mundodi S, Rhee SY, Apweiler R, Barrell D, Camon E, Dimmer E, Lee V, Chisholm R, Gaudet P, Kibbe W, Kishore R, Schwarz EM, Sternberg P, Gwinn M, Hannick L, Wortman J, Berriman M, Wood V, de la CN, Tonellato P, Jaiswal P, Seigfried T, White R: The Gene Ontology (GO) database and informatics resource. Nucleic Acids Res 2004, 32:D258-D26I.

10. Ashburner M, Mungall CJ, Lewis SE: Ontologies for biologists: a community model for the annotation of genomic data. Cold Spring Harb Symp Quant Biol 2003, 68:227-235.

II. Diehn M, Alizadeh AA, Rando OJ, Liu CL, Stankunas K, Botstein D, Crabtree GR, Brown PO: Genomic expression programs and the integration of the CD28 costimulatory signal in $\mathrm{T}$ cell activation. Proc Natl Acad Sci U S A 2002, 99: I I796-I I80 I.

12. Kane LP, Lin J, Weiss A: Signal transduction by the TCR for antigen. Curr Opin Immunol 2000, I 2:242-249.

13. Lin Z, Fillmore GC, Um TH, Elenitoba-Johnson KS, Lim MS: Comparative microarray analysis of gene expression during activation of human peripheral blood $\mathbf{T}$ cells and leukemic Jurkat T cells. Lab Invest 2003, 83:765-776.

14. Smith JL, Freebern WJ, Collins I, De Siervi A, Montano I, Haggerty CM, McNutt MC, Butscher WG, Dzekunova I, Petersen DW, Kawasaki E, Merchant JL, Gardner K: Kinetic profiles of p300 occupancy in vivo predict common features of promoter structure and coactivator recruitment. Proc Natl Acad Sci U S A 2004, I01:11554-11559.

15. Alter O, Brown PO, Botstein D: Singular value decomposition for genome-wide expression data processing and modeling. Proc Natl Acad Sci U S A 2000, 97:10101-10106.

16. Zeeberg BR, Feng W, Wang G, Wang MD, Fojo AT, Sunshine M, Narasimhan S, Kane DW, Reinhold WC, Lababidi S, Bussey KJ, Riss J, Barrett JC, Weinstein JN: GoMiner: a resource for biological interpretation of genomic and proteomic data. Genome Biol 2003, 4:R28.

17. Moses AM, Chiang DY, Kellis M, Lander ES, Eisen MB: Position specific variation in the rate of evolution in transcription factor binding sites. BMC Evol Biol 2003, 3:19.

18. Hilger-Eversheim K, Moser M, Schorle H, Buettner R: Regulatory roles of AP-2 transcription factors in vertebrate development, apoptosis and cell-cycle control. Gene 2000, 260:1-12.

19. Bar-Eli M: Gene regulation in melanoma progression by the AP-2 transcription factor. Pigment Cell Res 200I, I 4:78-85.

20. Benson LQ, Coon MR, Krueger LM, Han GC, Sarnaik AA, Wechsler DS: Expression of $\mathrm{MXII}$, a Myc antagonist, is regulated by Sp I and AP2. J Biol Chem I 999, 274:28794-28802.

21. Adamson E, de BI, Mittal S, Wang Y, Hayakawa J, Korkmaz K, O'Hagan D, McClelland M, Mercola D: Egr I signaling in prostate cancer. Cancer Biol Ther 2003, 2:617-622.

22. Gaboli M, Kotsi PA, Gurrieri C, Cattoretti G, Ronchetti S, CordonCardo C, Broxmeyer HE, Hromas R, Pandolfi PP: MzfI controls cell proliferation and tumorigenesis. Genes Dev 200 I, I 5: 1625-I630.

23. Hromas R, Davis B, Rauscher FJIII, Klemsz M, Tenen D, Hoffman S, $\mathrm{Xu} D$, Morris JF: Hematopoietic transcriptional regulation by the myeloid zinc finger gene, MZF-I. Curr Top Microbiol Immunol 1996, 2 I I: I59-164.

24. Lin A, Karin M: NF-kappaB in cancer: a marked target. Semin Cancer Biol 2003, 13:107-114.

25. Copertino DW, Jenkinson S, Jones FS, Edelman GM: Structural and functional similarities between the promoters for mouse tenascin and chicken cytotactin. Proc Natl Acad Sci U S A 1995, 92:2131-2135.

26. lademarco MF, McQuillan JJ, Dean DC: Vascular cell adhesion molecule I: contrasting transcriptional control mechanisms in muscle and endothelium. Proc Natl Acad Sci U S A 1993, 90:3943-3947.

27. Greenbaum S, Zhuang Y: Regulation of early lymphocyte development by E2A family proteins. Semin Immunol 2002, |4:405-4|4.

28. Genetta T, Ruezinsky D, Kadesch T: Displacement of an E-boxbinding repressor by basic helix-loop-helix proteins: implications for B-cell specificity of the immunoglobulin heavy-chain enhancer. Mol Cell Biol 1994, I4:6I53-6I63.

29. Postigo AA, Dean DC: Independent repressor domains in ZEB regulate muscle and T-cell differentiation. Mol Cell Biol 1999, 19:796 I-797|.

30. 2005 [http://genome.ucsc.edu].

31. Palaniswamy SK, Jin VX, Sun H, Davuluri RV: OMGProm: a database of orthologous mammalian gene promoters. Bioinformatics 2005, 21:835-836.

32. Suzuki Y, Yamashita R, Nakai K, Sugano S: DBTSS: DataBase of human Transcriptional Start Sites and full-length cDNAs. Nucleic Acids Res 2002, 30:328-331.

33. Landry JR, Mager DL, Wilhelm BT: Complex controls: the role of alternative promoters in mammalian genomes. Trends Genet 2003, 19:640-648.

34. Levine $M$, Tjian $R$ : Transcription regulation and animal diversity. Nature 2003, 424:|47-I5I. 
35. Butler JE, Kadonaga JT: The RNA polymerase II core promoter: a key component in the regulation of gene expression. Genes Dev 2002, 16:2583-2592.

36. Butler JE, Kadonaga JT: Enhancer-promoter specificity mediated by DPE or TATA core promoter motifs. Genes Dev 200I, I5:25I5-25।9.

37. Tompa M, Li N, Bailey TL, Church GM, De Moor B, Eskin E, Favorov AV, Frith MC, Fu Y, Kent WJ, Makeev VJ, Mironov AA, Noble WS, Pavesi G, Pesole G, Regnier M, Simonis N, Sinha S, Thiis G, van Helden J, Vandenbogaert M, Weng Z, Workman C, Ye C, Zhu Z: Assessing computational tools for the discovery of transcription factor binding sites. Nat Biotechnol 2005, 23:137-I44.

38. Serfling $E$, Avots $A$, Neumann $M$ : The architecture of the interleukin-2 promoter: a reflection of $\mathrm{T}$ lymphocyte activation. Biochim Biophys Acta 1995, 1263: I8I-200.

39. Shapiro VS, Truitt KE, Imboden JB, Weiss A: CD28 mediates transcriptional upregulation of the interleukin-2 (IL-2) promoter through a composite element containing the CD28RE and NF-IL-2B AP-I sites. Mol Cell Biol 1997, 1 7:405 I-4058.

40. Butscher WG, Powers C, Olive M, Vinson C, Gardner K: Coordinate transactivation of the interleukin-2 CD28 response element by c-Rel and ATF-I/CREB2. J Biol Chem 1998, 273:552-560.

4I. Sun YL, Glimcher LH, Hoey T: Novel nfat sites that mediate activation of the interleukin-2 promoter in response to $t$-cell receptor stimulation. Mol Cell Biol I995, I5:6299-63I0.

42. Powell JD, Lerner CG, Ewoldt GR, Schwartz RH: The $-\mathbf{I 8 0}$ site of the IL-2 promoter is the target of CREB/CREM binding in T cell anergy. J Immunol 1999, 163:663I-6639.

43. Rockman MV, Hahn MW, Soranzo N, Loisel DA, Goldstein DB, Wray GA: Positive selection on MMP3 regulation has shaped heart disease risk. Curr Biol 2004, I 4:153I-1539.

44. Phair RD, Misteli T: High mobility of proteins in the mammalian cell nucleus. Nature 2000, 404:604-609.

45. Gardiner-Garden M, Frommer M: CpG islands in vertebrate genomes. J Mol Biol 1987, 196:261-282.

46. Yamashita R, Suzuki Y, Sugano S, Nakai K: Genome-wide analysis reveals strong correlation between $C p G$ islands with nearby transcription start sites of genes and their tissue specificity. Gene 2005, 350:129-136.

47. Stepanova M, Tiazhelova T, Skoblov M, Baranova A: A comparative analysis of relative occurrence of transcription factor binding sites in vertebrate genomes and gene promoter areas. Bioinformatics 2005, 21:1789-1796.

48. Tullai JW, Schaffer ME, Mullenbrock S, Kasif S, Cooper GM: Identification of transcription factor binding sites upstream of human genes regulated by the phosphatidylinositol 3-kinase and MEK/ERK signaling pathways. I Biol Chem 2004, 279:20167-20177.

49. Tavazoie S, Hughes JD, Campbell MJ, Cho RJ, Church GM: Systematic determination of genetic network architecture. Nat Genet 1999, 22:28I-285.

50. Bluthgen N, Kielbasa SM, Herzel H: Inferring combinatorial regulation of transcription in silico. Nucleic Acids Res 2005 33:272-279

5I. Matys V, Fricke E, Geffers R, Gossling E, Haubrock M, Hehl R, Hornischer K, Karas D, Kel AE, Kel-Margoulis OV, Kloos DU, Land S, Lewicki-Potapov B, Michael H, Munch R, Reuter I, Rotert S, Saxel H, Scheer $M$, Thiele $S$, Wingender E: TRANSFAC: transcriptional regulation, from patterns to profiles. Nucleic Acids Res 2003, $31: 374-378$

52. Dougherty ER, Barrera J, Brun M, Kim S, Cesar RM, Chen Y, Bittner $M$, Trent JM: Inference from clustering with application to gene-expression microarrays. J Comput Biol 2002, 9: I05- 26.

53. Davies DL, Bouldin DW: A cluster separation measure. IEEE Transactions on Pattern Analysis and Machine Intelligence 1979, I :224-227.
Publish with Bio Med Central and every scientist can read your work free of charge

"BioMed Central will be the most significant development for disseminating the results of biomedical research in our lifetime. "

Sir Paul Nurse, Cancer Research UK

Your research papers will be:

- available free of charge to the entire biomedical community

- peer reviewed and published immediately upon acceptance

- cited in PubMed and archived on PubMed Central

- yours - you keep the copyright
BioMedcentral 